\title{
A new subgenus of Pterostichus (Coleoptera: Carabidae: Pterostichini) with 14 new species from Vietnam
}

\section{Новый подрод Pterostichus (Coleoptera: Carabidae: Pterostichini) с 14 новыми видами из Вьетнама}

\author{
D.N. Fedorenko \\ A.H. Федоренко
}

\begin{abstract}
A.N. Severtsov Institute of ecology and evolution, Leninsky pr. 33, Moscow 119071, Russia. E-mail: dmitri-fedorenko@yandex.ru Институт проблем экологии и эволюции им. А.Н. Северцова, Российская Академия Наук, Ленинский пр-т, 33, Москва 119071, Россия.
\end{abstract}

KEY WORDS: Coleoptera, Carabidae, Pterostichus, Vietosteropus, new subgenus, new species, new subspecies, Vietnam, Oriental region.

КЛЮЧЕВЫЕ СЛОВА: Coleoptera, Carabidae, Pterostichus, новый подрод, новый вид, новый подвид, Вьетнам, Ориентальная область.

ABSTRACT. A new subgenus, Vietosteropus subg.n., of the genus Pterostichus Bonelli, 1810 is erected for 16 species from Vietnam, including 14 new species, $P$. abramovi sp.n., $P$. anichkini sp.n., $P$. bidoupensis sp.n., $P$. chupanphan sp.n., $P$. dalatensis sp.n., $P$. gialaiensis sp.n., $P$. honbaensis sp.n., $P$. konchurang sp.n., $P$. konplongensis sp.n., $P$. kontumensis sp.n., $P$. ngokboci sp.n., $P$. ngoclinhensis sp.n., $P$. semiopacus sp.n., $P$. sulcicollis sp.n., and one new subspecies, $P$. annamita chuyangsin ssp.n. New taxa are described and illustrated. The species are arranged in to two species groups. A key to species is provided.

РЕЗЮМЕ. Новый подрод Vietosteropus subg.n. рода Pterostichus Bonelli, 1810 установлен для 16 видов из Вьетнама. Даны описания подрода, а также 14 новых видов и 1 нового подвида: P. abramovi sp.n., $P$. anichkini sp.n., $P$. bidoupensis sp.n., $P$. chupanphan sp.n., $P$. dalatensis sp.n., $P$. gialaiensis sp.n., $P$. honbaensis sp.n., $P$. konchurang sp.n., $P$. konplongensis sp.n., P. kontumensis sp.n., P. ngokboci sp.n., $P$. ngoclinhensis sp.n., $P$. semiopacus sp.n., $P$. sulcicollis sp.n., P. annamita chuyangsin ssp.n. Виды распределены по двум группам; составлена таблица для их определения.

\section{Introduction}

Pterostichus Bonelli, 1810 is a speciose genus widespread in the Northern Hemisphere. Numerous new taxa of Pterostichus, including subgenera, species groups, species, and subspecies, were described from China over the recent decades [Allegro, Sciaky, 2010; Sciaky, 1994a-c, 1995, 1996a-c, 1997; Sciaky, Allegro, 2013; Sciaky, Faccini, 2003; Sciaky, Wrase, 1997; Shi, Liang, 2015; Shi et al., 2013; Wrase, Schmidt, 2006]. Howev- er, there are no recent comprehensive treatments of Pterostichus of China and Indochina other than revisions or reviews of individual subgenera [Allegro, Sciaky, 2010; Faccini, Sciaky, 2000; Sciaky, 1994b; Sciaky, Allegro, 2013; Sciaky, Faccini, 2003; Schmidt, 2006, 2012; Shi et al., 2013; Shi, Liang, 2015].

Pterostichini of Indochina, including Vietnam, are little known, other than a few Pterostichus species recently described or reported from Indochina and adjacent lands [Straneo, 1939, 1949, 1979, 1984; Morvan, 1992; Wrase, Schmidt, 2006]. Below we describe 14 new species from Vietnam closely related to $P$. annamita (Straneo, 1939) and $P$. cavicollis Straneo, 1984. These species altogether form a separate, probably monophyletic, group, for which a new subgenus is erected.

A major part of the material was collected during recent expeditions to highlands of southern and central Vietnam, sponsored by the Russia-Vietnam Tropical Center.

Acronyms used are as follows: MSNM, Museo Civico di Storia Naturale di Milano; SIEE, the author's reference collection at A.N. Severtsov Institute of Ecology \& Evolution, Russian Academy of Sciences, Moscow; ZISP, Zoological Institute, Russian Academy of Sciences, St. Petersburg; ZMMU, Zoological Museum of the Moscow State University.

The following parameters were analyzed: maximum body length measured between apices of closed mandibles and apex of elytra (BL); distance between base of elytron and discal pore d2 (D2); length of elytron, measured from the lowest point of basal ridge to apex (EL); maximum width of elytra (EW); width of head across eyes (HW); length of pronotum along median line (PL); maximum width of pronotum (PW).

Measurements were taken using an eyepiece micrometer, to two decimal places. The number of specimens 
measured (n) is only given for the first ratio in the description. All labels are printed, unless marked '[hw]' (= handwritten). Data on labels of type specimens are in quotes.

\section{Results}

Vietosteropus Fedorenko, subg.n.

Type species: Feronia annamita Straneo, 1939.

DESCRIPTION. Body (Figs 19-34) small- to largesized, shiny black, without or with slight iridescence; elytra sometimes dull. Dorsum with meshed microsculpture; meshes very small, isodiametric and superficial on head, transverse and rather widely orthogonal over pronotal disc, isodiametric to strongly transverse on elytra. Reflexed lateral margin of elytra, elytral striae at bottom and sometimes also explanate lateral margin of pronotum with isodiametric, somewhat alveolate, often coarse microsculpture.

Head large; eyes medium-sized, moderately convex to rather flat; genae distinct, slightly to much shorter than eyes. Two supra-ocular setae inserted just inside deep supra-ocular groove. Neck constriction faint to missing. Frontal foveae sulciform (accordingly, named frontal sulci hereafter), fairly short, impunctate, very deep to obliterate, diverging and straight to slightly S-shaped; when developed, abruptly disappearing on a level with or just before anterior supra-ocular seta. Clypeus very gently sinuate, labrum truncate to gently sinuate. Antennae moderately long, pubescent from antennomere 4 onwards, antennomere 3 with no setae other than verticellate ones.

Mandibles moderately long, scrobe with a distinct longitudinal sulcus. Mentum with a bifid median tooth and two close setae at its base; borderlines between lateral lobes and epilobes extended into grooves converging basad and ending in small and deep pits in front of mentum suture. Submentum short, transversely costate or subcarinate, posteriorly limited by a fairly deep transverse excavation; quadrisetose or bisetose, outer setae being much shorter or totally reduced, respectively. Terminal labial palpomere subfusiform, subcylindric in apical half; penultimate labial palpomere bisetose.

Pronotum mostly (sub)circular, with sides rounded or straight in basal half; basal angles very obtuse to rounded off. Lateral margin rather widely explanate, gradually broadening basad; lateral groove narrow to wide, deep or very deep, abruptly disappeared a fourth from base, with explanate lateral margin slightly broadened behind. Base gently to conspicuously sinuate at middle. Inner basal sulci moderately long yet rather superficial, mostly converging slightly apicad and obliterate just basally; often obliterate, sometimes deep. Outer basal sulcus as a shallower S-shaped extension of lateral groove towards and slightly inside base (including also a remnant of basal bead outside inner sulcus). Basal foveae impunctate to densely punctate between and often also at bottom of basal sulci. Apex evenly and moderately sinuate to truncate; apical bead obliterate in middle third. Anterolateral seta in lateral groove, posterolateral seta on explanate lateral margin near (site of) basal angle.

Elytra elliptic, broadest at or just behind the middle, sometimes nearly parallel-sided. Base truncate and fairly narrow; humeri prominent yet rounded, without teeth. Sides rounded behind humeri, often slightly diverging and straight to indistinctly concave in basal third to half, distinctly sinuate before apex; apices blunt or narrowly rounded. Basal ridge entire, convex latero-apicad, distinctly higher at humerus than at suture, humeral angle opposite or outside stria 7 , usually obtuse. Internal preapical plica well-developed in most species. Striae impunctate (except in 1-2 species), deep or very deep. Intervals convex, more so before apex and towards lateral margin, 1st merged in lateral edge (apical bead) at sutural angle, 2nd separate apically, 7th, 5th and 3rd (rarely 7 th and 3rd) confluent apicad in succession. Interval 8 often much narrower than 7 th. Reflexed lateral margin often slightly broadened in front of apical sinuation, with an additional convex interval outside stria 9 (accordingly, termed 'interval 10' hereafter: Figs 9-11). Parascutellar striole mostly vestigial to obliterate. Parascutellar seta present, interval 3 with seta $\mathrm{d} 2$ adjoining stria 2 at middle. Interval 9 with 15-25 umbilical setae (USS) in a continuous series; USS often slightly sparser in second fourth.

Prosternum with a shallow to indistinct longitudinal groove; prosternal process not beaded, with apical declivity subconvex to slightly concave and more or less distinctly carinate or finely beaded on sides. Mesoventrite with a small precoxal tubercle. Metepisternum short, about as wide as or wider than long. Abdomen finely beaded on sides, often except for sternites II and III. Underside smooth; metepisternum, sides of mesothoracic peduncle (within oblique concavity of mesepisternum), metaventrite and abdominal sternites II and III more or less densely, finely to moderately, punctate.

Legs moderately strong. Proibiae slightly dilated apicad, with two posterolateral apical spinules and one posterior apical spinule. Metatrochanter ( $\operatorname{tr} 3$ ) rounded apically, about half as long as metafemur ( $f e 3)$. Tarsomeres $(\mathrm{tm}) 1-3$ of mesotarsi (ta2) and metatarsi (ta3) with outer (anterior) longitudinal carina limited by a sulcus on each side. Leg chetotaxy: profemur ( $f e l)$ posteriorly with three setae (basal, ventromedial, and preapical, as usual in Pterostichus); mesofemur in apical half with two anteroventral setae and two anterodorsal setae; metacoxa bisetose (inner seta missing); tr 3 asetose; $f e 3$ unisetose (distal anteroventral seta missing except in one species); metatibia ( $t i 3$ ) with $0-5$ strong setae along outer margin; $t m 1-4$ each with one pair of latero-apical setae, $t m 1-2$ each with one pair of dorso-apical setae; tm5 glabrous ventrally.

Aedeagus median lobe (Figs 35-58) arcuate to nearly geniculate in lateral view; right paramere long to short (Figs 59-87). When everted and inflated, internal sac bent ventrad or slightly to the left and then ventrad, with the following larger or smaller protrusions (Figs 12-13): large left preapical bulb (PBL), one or two fairly large bulbs on right side (PBR), and four small, spinulose, apical vesicles, or sclerites (av1-av4), around gonopore. PBL prominent, mostly bipartite to tetrapartite, depending on respective number of inner (lvi) and outer (lvl-lv3) vesicles. PBR varying from indistinct to divided into two parts or separate bulbs, dorsal (PBRd) and ventral (PBRv); sometimes left basal bulb (BB) present.

Female genitalia and reproductive tract (Figs 14-18). Gonosubcoxite with a row of dense setae along oblique apical margin. Gonocoxite falcate, slightly shorer than gonosubcoxite, with a double nematiform seta near apex and two ensiform setae at each ridge, ventral (outer) and dorsal (inner). Bursa copulatrix with a large, moderately sclerotized, hemispherical, apical invagination and a compact semicircular structure at base of spermathecal basal sclerite $(s b s)$. Seminal canal ( $s c$ ) serpentine, basally reinforced with falcate $s b s$, ending in a recurved cylindrical receptaculum ( $r p)$, with spermathecal gland duct entering this curve. Apex of $s b s$ separated well from $s c$.

Secondary sexual differences: Males are distinctive from females in having abdominal sternite VII bisetose (vs. quad- 
risetose); protarsomeres $1-3$ dilated and biserially squamose on ventral side; femora, $t i 2$ and $t i 3$ barely wider; $t i 2$ subangulate and slightly tuberculate along inner margin; $t i 3$ tuberculate along posteromesal ridge (vs. $t i 2$ and $t i 3$ inter- nally flat and smooth - compare Figs 1, 3, 5 with Figs 2, 4, 6). In the anamita-subgroup, males differentiated also by additional ventrobasal tubercle, distinct on $f e l$ while minute on $f e 3$ (Figs 1, 3).
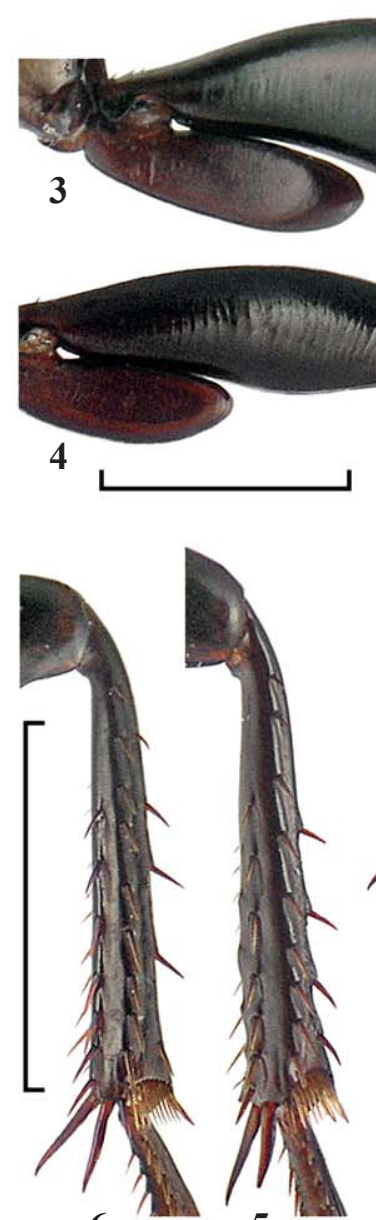

6

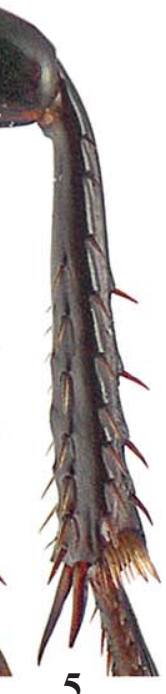

5

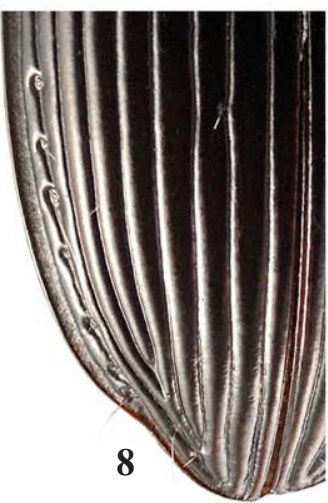

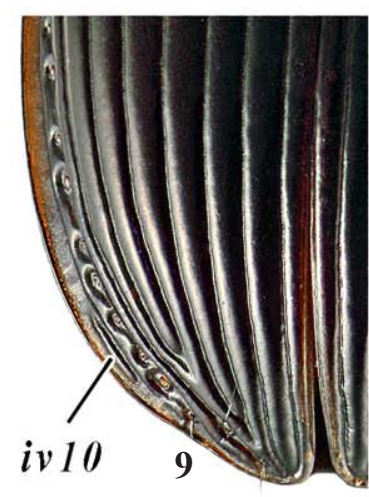

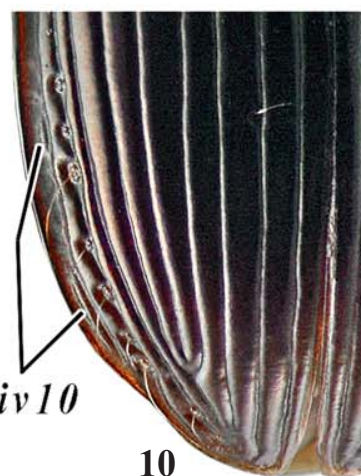

10
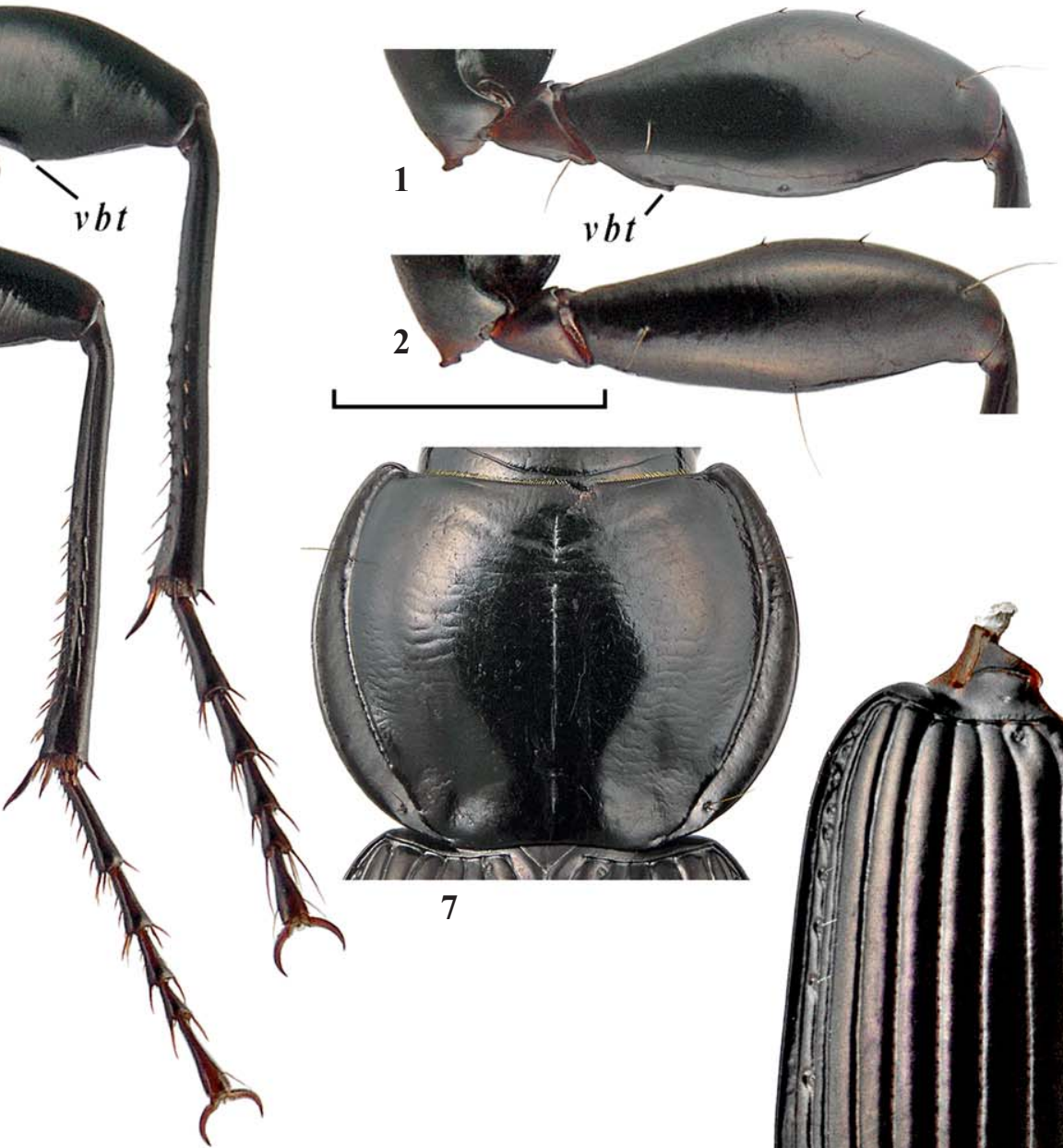

Figs 1-11. Pterostichus (Vietosteropus subgen.n.): 1-6, $11-$ P.bidoupensis sp.n.; 7 - P. annamita; 8 - P. ngoclinhensis sp.n.; $9-$ P. honbaensis sp.n.; 10 - P. kontumensis sp.n.; 1-2 - right profemur, caudal aspect; 3-4 - hind leg, dorsal aspect; 5-6 - mesotibia, caudal aspect; 7 - pronotum, dorsal aspect; 8-11 — left elytron, left dorsolateral aspect; $1,3,5-\mathrm{O}^{\top} ; 2,4,6$ - $;$; vbt - ventrobasal tubercle; iv10 additional interval 10. Scale bars: $1 \mathrm{~mm}$.

Рис. 1-11. Pterostichus (Vietosteropus subgen.n.): 1-6, $11-$ P.bidoupensis sp.n.; 7 - P. annamita; 8 - P. ngoclinhensis sp.n.; $9-$ P. honbaensis sp.n.; $10-P$. kontumensis sp.n.; 1-2 - переднее бедро, сзади; 3-4 - задняя нога, дорсально; 5-6 - средняя голень, сзади; 7 — переднеспинка, сверху; 8-11 - левое надкрылье, слева и сверху; 1 , 3, 5 — $0^{7} ; 2,4,6$ — $;$; $v t$ — вентробазальный бугорок; iv10 - дополнительный промежуток 10. Масштаб: 1 мм. 


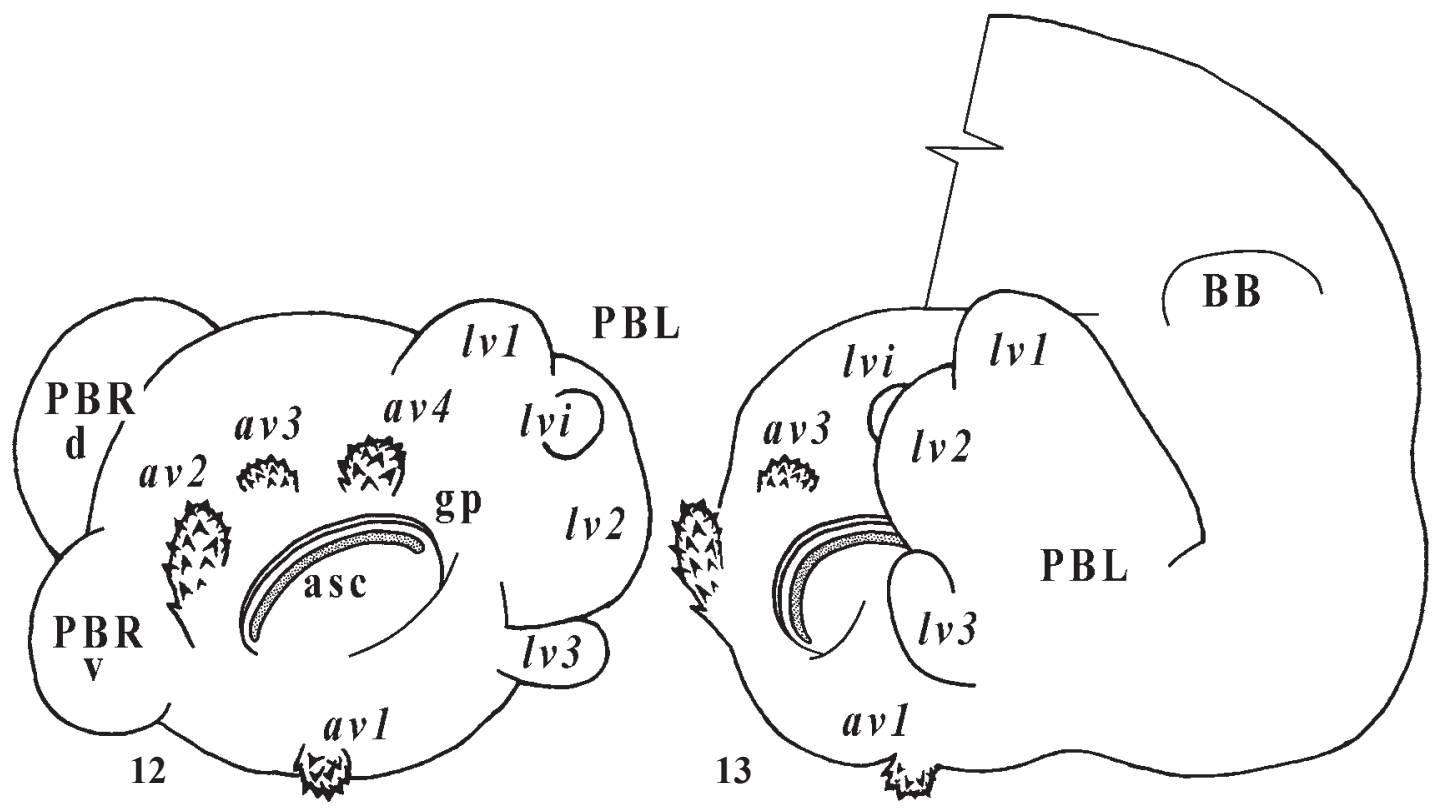

Figs 12-13. Pterostichus (Vietosteropus subgen.n.), generalized everted and inflated endophallus, caudal (14) and left (15) aspects; asc — apical semicircular sclerite; $a v 1-a v 4$ - apical vesicles: $a v 1$ - ventral; av2 — right; av3 — right dorsolateral; av4 — dorsal; BB — left basal bulb; $g p$ - gonopore; $l v$ - left vesicles, or protrusions of PBL: $l v 1$ - proximal; $l v 2$ - medial; $l v 3$ - distal; $l v i-$ inner; PBL — left preapical bulb; PBR — right preapical bulb; dorsal (d) and ventral (v).

Рис. 12-13. Pterostichus (Vietosteropus subgen.n.), генерализованный вывернутый и раздутый эндофаллус, вид сзади (14) и слева (15); asc - апикальный полукольцевой склерит; av1-av4 - апикальные пузырьки: av1 — вентральный; av2 - правый; av3 - правый верхний; av4 - дорзальный; BB - левый базальный пузырь; $g p$ - гонопор; $l v$ - левые пузырьки, или выпячивания PBL: $l v 1$ проксимальный; lv2 - медиальный; lv3 - дистальный; lvi - внутренний; PBL - левый предвершинный пузырь; PBR правый предвершинные пузыри, дорзальный (d) и вентральный (v).

DIAGNOSIS. A subgenus of Pterostichus by the following features: Body rather convex, medium-sized for the genus. Head bisetose above each eye; terminal labial palpomere subfusiform; frontal foveae short, sulciform, impunctate and strongly diverging. Pronotum distinctive: quadrisetose, rather widely explanate laterally, not sinuate on sides; basal angles rather widely rounded to indistinct; basal fovea and inner basal sulcus mostly shallow to indistinct; outer basal sulcus anteriorly merged into lateral groove. Elytron with parascutellar seta; parascutellar striole mostly short or missing; interval 3 with one discal seta adjoining stria 2 at middle; metepisterna short following apterous condition. Chetotaxy of the body, especially of the legs, as for many advanced lineages of Pterostichus: mesotibia anteriorly 2+2-setose, metacoxa bisetose laterally (inner seta missing), metatrochanter asetose, metafemur with only proximal anteroventral seta (distal seta missing); tarsomere 5 glabrous ventrally. Mesotarsi and metatarsi with conspicuous outer carinae. Abdominal sternite VII smooth in both sexes. Aedeagus largely geniculate; everted and inflated internal sac bent to the left and/or ventrad.

NAME. Abbreviated combination of 'Vietnam' and 'Steropus', a subgenus of Pterostichus.

DISTRIBUTION. The subgenus includes 15 species with restricted ranges, confined to the Tay Nguen Plateau (or Central Highlands) within Kon Tum, Gia Lai, Dak Lak, Lam Dong and Khanh Hoa provinces in central and southern Vietnam. The species are about equally divided between two regions: the Dalat Plateau (Dak Lak, Lam Dong, and Khanh Hoa provinces), including the Dak Lak Plateau; and the northern part of the Tay Nguen Plateau that includes highlands south of the Truong Son mountain ridge. One additional species is known from northern Vietnam.

Five species $(P$. ngoclinhensis sp.n., $P$. konplongensis sp.n., $P$. kontumensis sp.n., $P$. sulcicollis sp.n. and $P$. anichkini sp.n.) occur in the Ngoc Linh Mts, three to four in the Bi Doup - Nui Ba Nature Reserve ( $P$. bidoupensis sp.n., $P$. semiopacus sp.n., $P$. dalatensis sp.n., and probably also P. annamita) and three in the Chu Yang Sin National park (P. annamita chuyangsin ssp.n., P. abramovi sp.n., and $P$. chupanphan sp.n.). Two species have been recorded in the Ngok Boc Mts (P. konplongensis sp.n. and P. ngokboci sp.n.) and in the Hon Ba Mts ( $P$. annamita and $P$. honbaensis sp.n.). Where three or more listed species are sympatric, mostly two of them share most or at least some habitats within an altitude range, whereas the remaining species occur(s) at higher or lower altitudes.

HABITS AND HABITATS. Most species have been collected by pitfall traps in monsoon broad-leaved or mixed forests at 970-1900 m altitudes. Adults dwell in leaf-litter, often near or under logs and tree trunks on the ground.

COMMENTS. The species of Vietosteropus subgen.n. are here arranged into three species groups readily differentiated by the combination of two characters, the width of elytral interval 8 and the body size. The annamita-group is defined by a larger body and the elytral interval 8 much narrower than 7 th; small-sized species with interval 8 as wide as 7 th belong to the dalatensis-group; The only species of the gialaiensis-group is larger-sized with subequally wide intervals 7 and 8 .

$P$. cavicollis is provisionally placed in the subgenus near the dalatensis-group. 


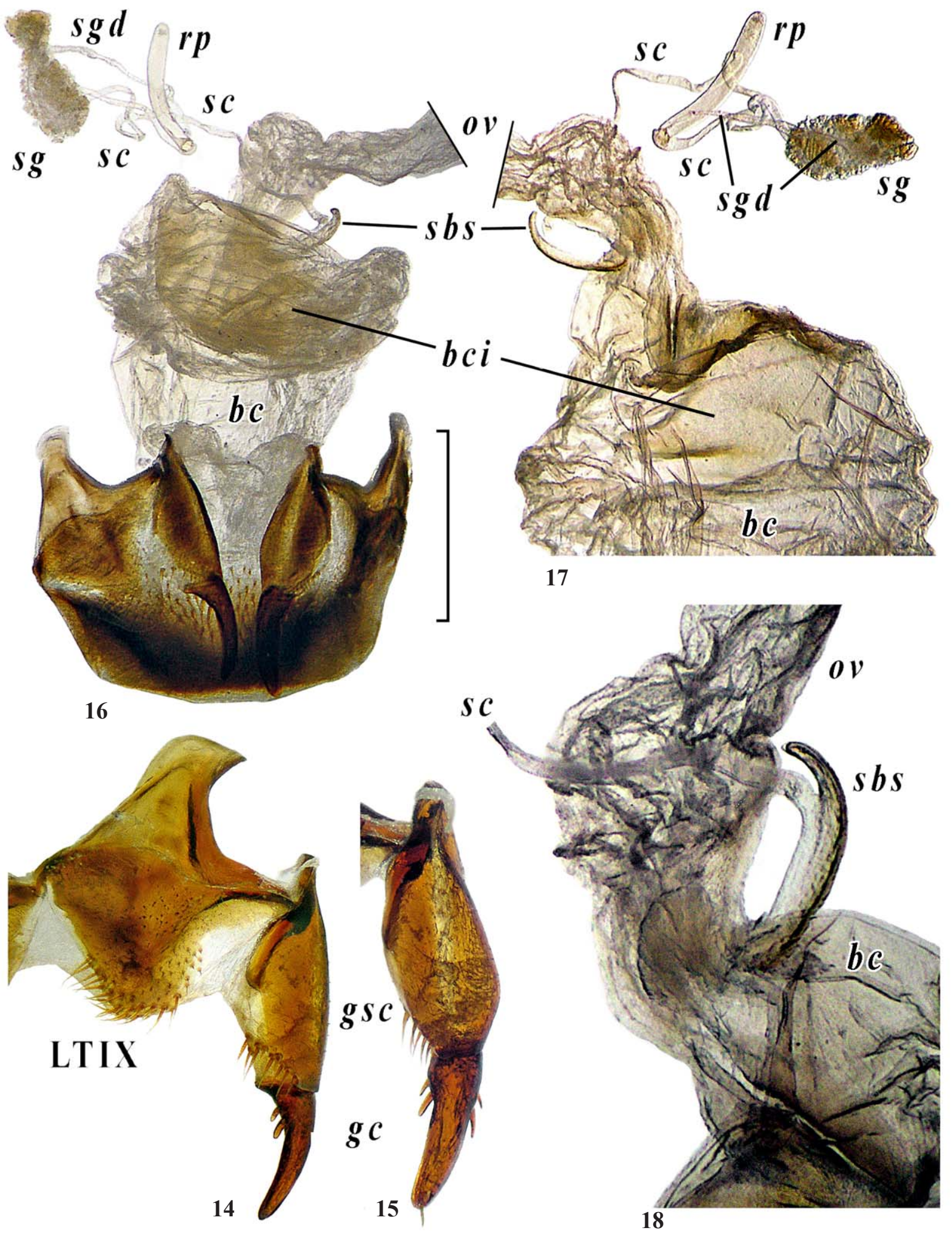

Figs 14-18. Female genitalia (14-15) and reproductive tract of Pterostichus bidoupensis sp.n.: bc - bursa copulatrix; bci - apical sclerotized invagination; $g c$ - gonocoxite; $g s c$ - gonosubcoxite; LTIX — laterotergite IX; $o v$ - common oviduct; $r$ - receptaculum; $s b s-$ spermathecal basal sclerite; $s c$ — seminal canal; $s g$ — spermathecal gland; $s g d$ — spermathecal gland duct; 14, 16 — ventral aspect; 15 left aspect; $17-18$ - dorsal aspect. Scale bar: $1 \mathrm{~mm}$.

Рис. 14-18. Гениталии и половые пути самки Pterostichus bidoupensis sp.n.: $b c-$ копулятивная сумка; $b c i-$ вершинное склеротизованное впячивание; $g c$ - гонококсит; gsc — гоносубкоксит; LT IX - латеротергит IX; $o v-$ общий яйцевод; $r-$ рецептакулум; $s b s$ - базальный склерит сперматеки; $s c$ - семенной канал; $s g$ - железа сперматеки; $s g d$ - проток железы сперматеки; 14, 16 - вентрально; 15 - слева; 17-18 - дорсально. Масштаб: 1 мм. 

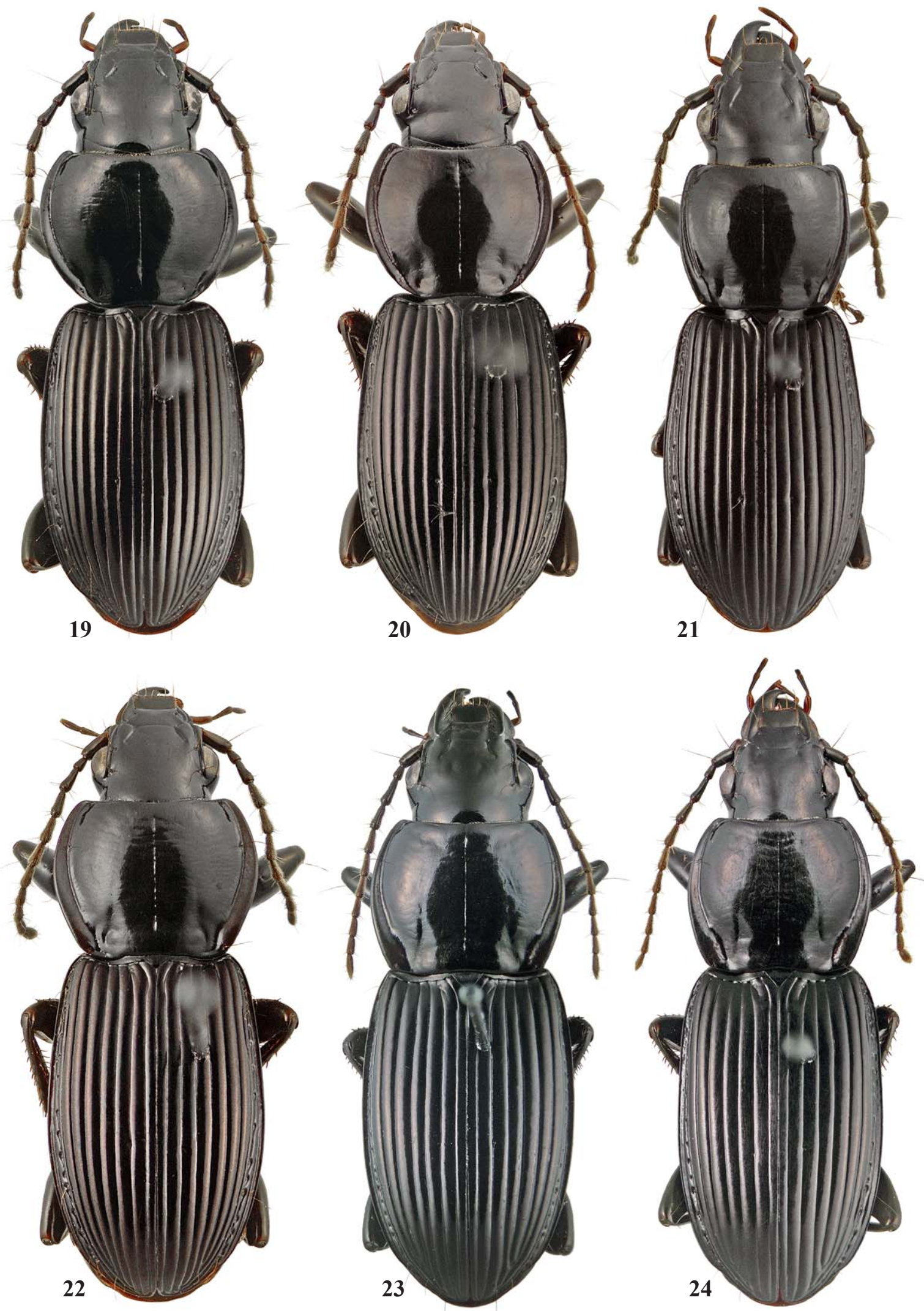

Figs 19-24. Dorsal habitus: 19 - Pterostichus annamita chuyangsin ssp.n.; 20 - P. bidoupensis sp.n.; 21 - P. semiopacus sp.n.; $22-$ P. abramovi sp.n., $23-P$. konchurang sp.n.; $24-$ P. ngokboci sp.n.

Рис. 19-26. Габитус дорзально: 19 - Pterostichus annamita chuyangsin ssp.n.; 20 - P. bidoupensis sp.n.; 21 - P. semiopacus sp.n.; $22-$ P. abramovi sp.n.; $23-P$. konchurang sp.n.; $24-P$. ngokboci sp.n. 

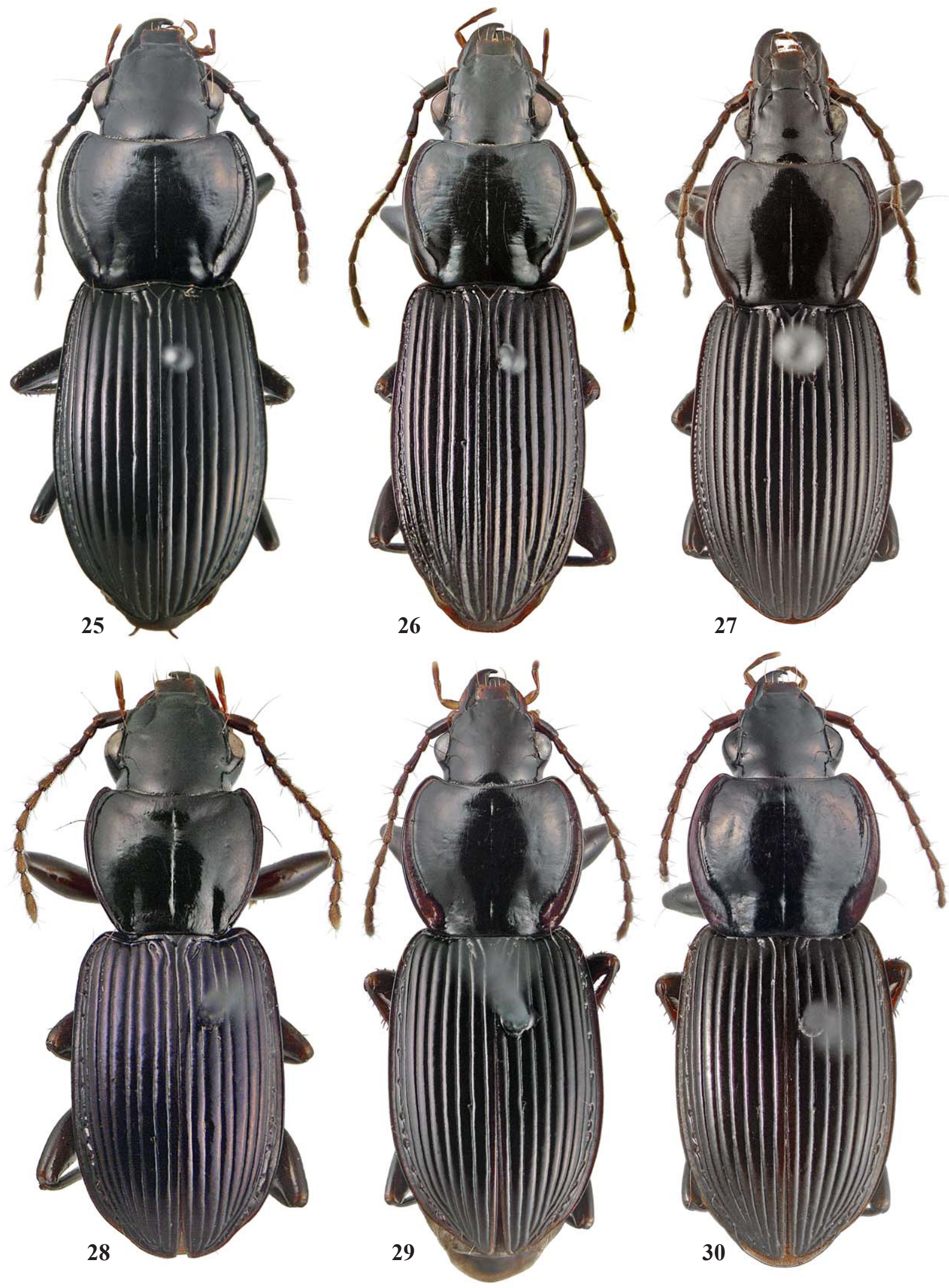

Figs 25-30. Dorsal habitus: 25 - Pterostichus sulcicollis sp.n.; 26 - P. anichkini sp.n.; 27 - P. gialaiensis sp.n.; 28 - P. kontumensis sp.n.; $29-P$. dalatensis sp.n.; $30-P$. honbaensis sp.n.

Рис. 25-30. Габитус дорзально: 25 - Pterostichus sulcicollis sp.n.; 26 - P. anichkini sp.n.; 27 - P. gialaiensis sp.n.; 28 P. kontumensis sp.n.; $29-P$. dalatensis sp.n.; $30-P$. honbaensis sp.n. 
KEY TO SPECIES OF VIETOSTEROPUS SUBGEN.N.

1(4) Elytral striae, especially outer ones, more or less distinctly punctate; interval 8 as wide as or barely narrower than 7; interval 10 missing.

2(3) Frontal sulci moderately deep. Elytra with widely rounded humeri, indistinct base and very finely punctate striae. Pronotum circular, without basal angles; apical bead entire or almost so. Submentum quadrisetose. Legs and antennae red. - Northern Vietnam. BL 13.2-16.5? mm.

16. $P$ cavicollis Straneo, 1984

(2) Frontal sulci very deep. Elytra with distinct base, rounded yet traceable humeri, and moderately punctate striae. Basal angles of pronotum rounded yet traceable. Submentum bisetose. Legs and antennae darker. BL $16.9 \mathrm{~mm}$. . 15. P. gialaiensis sp.n.

4(1) Elytral striae impunctate, sometimes very faintly crenulate; interval 10 present or not. Submentum bisetose or quadrisetose.

5(6) Pronotum subovate, distinctly wider apically than basally, with a fine lateral bead; inner basal sulcus very deep and reaching base. Body small, BL 9.5-10.2 mm. Elytra slightly violaceous, with intervals 3,5 and often also 7 distinctly broader than adjacent ones. Submentum bisetose. Abdominal sternites V-VII beaded laterally. Metatibia externally glabrous. Elytral interval 10 very short or broken.

14. P. kontumensis sp.n.

6(5) Pronotum circular to subquadrate, with lateral margin more or less widely explanate at least behind the middle; inner basal sulcus obliterate close to base. Body without violaceous metallic tinge.

7(24) Frontal sulci distinct and mostly deep.

8(19) Elytral interval 8 distinctly (usually much) narrower than 7 , mostly narrowly costate, more so basally and apically. BL $>13 \mathrm{~mm}$. Elytral microsculpture either subequally distinct throughout or coarser on disc than on lateral reflexed margin. Explanate lateral margin of pronotum flat or slightly convex.

9(16) Interval 10 running on apical 1/2-3/4 elytra. Frontal sulci deep or very so. Submentum bisetose. Right paramere long, arcuate to geniculate (Figs 59-67,71). - Species from the Dalat Plateau, southern Vietnam.

10(13) Pronotum circular, with basal angles rounded off, leaving elytral bases exposed. Elytral interval 10 reaching middle (Fig. 11). Elytral microsculpture moderately to very transverse. Metatibia externally glabrous; $f e l$ and $f e 3$ with a small ventrobasal tubercle (Figs 1,3 ) in male.

11(12) Elytra black; interval 8 much narrower than 7, costate all along. Pronotum smaller, EW/PW 1.12-1.18 (mean 1.14 ), with explanate lateral margin moderately and subequally wide throughout. Abdominal sternites II and often also III with faint or no lateral bead. Apex of aedeagus median lobe trapezoidal and rounded in dorsal view, right paramere geniculate, obtusely angulate between base and apex (Figs 49, 64). BL 13.5-16.4 mm.

2. P. bidoupensis sp.n.

12(11) Elytra black, with faint purplish tinge; interval 8 distinctly (often not much) narrower than 7 , both mostly subequally convex at middle. Pronotum slightly larger in general. Abdomen entirely beaded on sides. Apex of aedeagus median lobe subtriangular in dorsal view, right paramere arcuate (Figs 51, 60, 62)

a(b) Elytra indistinctly purplish from less transverse microsculpture. Pronotum very large, EW/PW 1.01-1.07 (mean 1.04), with explanate lateral margin much wider in basal two thirds than anteriorly (Fig.7). BL 15.1-17.8 $\mathrm{mm}$. 1a. P. a. annamita Straneo, 1939 b(a) Elytra with a distinct purplish tinge due to very transverse microsculpture. Pronotum slightly smaller, EW/ PW 1.05-1.14 (mean 1.10), with explanate lateral margin mostly subequally wide throughout or barely wider behind the middle (Fig. 19). BL 13.2-15.7 mm. 1b. P. annamita chuyangsin ssp.n.

13(10) Pronotum subcircular to subquadrate, with basal angles rounded yet traceable and largely obstructing elytral bases. Metatibia externally with $1-5$ setae; $f e l$ and $f e 3$ without ventrobasal tubercle in male.

14(15) Elytra dull from coarse isodiametric microsculpture; interval 10 running on apical three quarters. Pronotum subquadrate, fairly narrow; basal angles obtuse, apically rounded; lateral groove widely sulcate and very deep. Metafemur bisetose. BL 17.3-19.2 mm.

4. P. semiopacus sp.n.

15(14) Elytra shiny, with superficial transverse microsculpture; interval 10 behind the middle. Pronotum subcircular and wide; basal angles rounded; lateral groove very narrowly sulcate. Metafemur unisetose. BL 13-15.5 mm...

3. P. abramovi sp.n.

16(9) Elytron without interval 10. Submentum quadrisetose. Frontal sulci moderately deep to rather shallow. Submentum quadrisetose. Right paramere short falcate (Figs 68,73). - Species from highlands north of the Dalat Plateau.

17(18) Body large, BL 20.4-22.3 mm. Frontal sulci moderately deep. Abdominal sternite II without lateral bead. Underside largely impunctate. .............. 8. P. konchurang sp.n.

18(17) Body smaller, BL 17.9-18.5 mm. Frontal sulci rather shallow, more so posteriorly. Abdomen with entire lateral bead. Mesosternum, sides of metasternum and metepisterna distinctly punctate............... 7. P. ngokboci sp.n.

19(8) Elytral interval 8 as wide as 7. Elytral microsculpture very transverse and very superficial on disc, isodiametric and very coarse, slightly alveolate, on lateral reflexed margin. Explanate lateral margin of pronotum shallowly grooved at least behind apical angles, separating between disc and a faint lateral bead; basal foveae sparsely to densely punctate. Submentum quadrisetose in general. Metatibia externally glabrous. $\mathrm{BL}<13 \mathrm{~mm}$.

20(21) Pronotum bisetose due to posterolateral seta missing; inner basal sulcus deep; basal foveae very sparsely punctate at base to nearly impunctate. Elytron without interval 10. BL 10.6-11.8 mm......... 11. P. ngoclinhensis sp.n.

21(20) Pronotum quadrisetose; inner basal sulcus very shallow to missing; basal foveae distinctly punctate.

22(23) Elytron without interval 10. Pronotal basal foveae finely and not very densely punctate. BL $10.4-12.7 \mathrm{~mm}$. 12. P. konplongensis sp.n.

23(22) Elytron in apical third with interval 10. Pronotal basal foveae coarsely and densely punctate. BL $10.2-11.2 \mathrm{~mm}$. 13. P. chupanphan sp.n.

24(7) Frontal sulci obliterate or vague.

25(28) Elytral interval 8 as wide as 7, interval 10 preapical and short. Microsculpture moderately transverse and very superficial on elytral disc, isodiametric and very coarse on reflexed lateral margins of elytra and pronotum in apical half. Metatibia externally glabrous. Subentum bisetose. $\mathrm{BL}<11 \mathrm{~mm}$

26(27) Pronotal lateral bead distinct except basally. Abdominal sternites II and III not laterally beaded. Submentum flat. BL 9.3-10.8 mm. ............... 9. P. dalatensis sp.n.

27(26) Pronotal lateral bead indistinct. Abdomen entirely beaded along sides. Submentum as for the subgenus. BL $10-10.7 \mathrm{~mm}$. 10. $P$. honbaensis sp.n. 


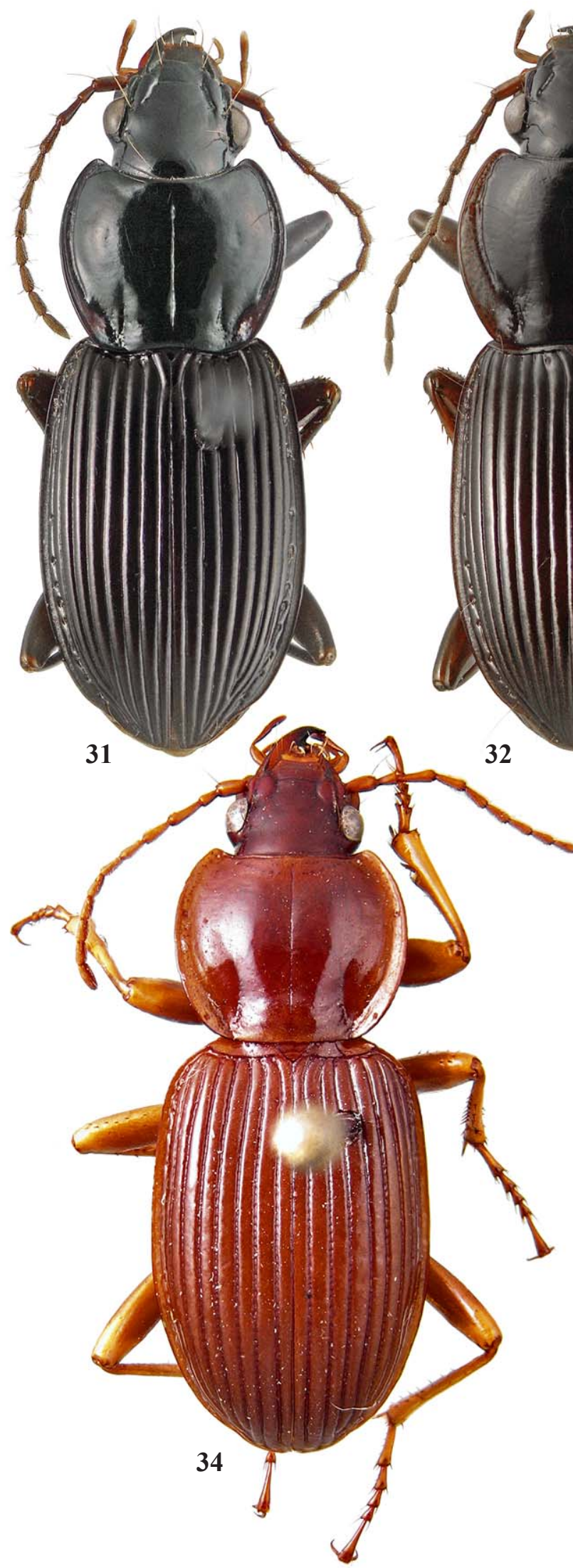

Figs 31-34. Dorsal habitus: $31-$ Pterostichus ngoclinhensis sp.n.; $32-P$. konplongensis sp.n.; $33-$ P. chupanphan sp.n.; $34-$ P. cavicollis, + paratype.

Рис. 31-34. Габитус дорзально: 31 - Pterostichus ngoclinhensis sp.n.; $32-P$. konplongensis sp.n.; $33-P$. chupanphan sp.n.; $34-P$. cavicollis, + паратип.

28(25) Elytral interval 8 narrowly costate to carinate, much narrower than 7; interval 10 missing; disc with isodiametric to moderately transverse microsculpture. Explanate lateral margin of pronotum flat to slightly convex; lateral groove widely sulcate and very deep. Submentum quadrisetose. Metatibia externally with $1-5$ setae.

29(30) Elytral intervals very convex before apex, 7 th, 5 th and 3rd confluent apicad in succession, 7th and 8th narrowly costate to subcarinate; microsculpture isodiametric. $\mathrm{BL}$ 16-18.1 mm. ............................. 5. P. sulcicollis sp.n. 30(28) Elytral intervals 3 and 7 only confluent apically; 3rd, 7th and 8th sharply carinate there; microsculpture isodiametric in female, slightly to moderately transverse in male. BL 17.8-19.4 mm. . 6. P. anichkini sp.n. 


\section{The annamita species group}

DESCRIPTION. Body medium- to large-sized, BL 13 $22.3 \mathrm{~mm}$. Elytra with interval 8 much narrower than 7 th. Pronotum with explanate lateral margin flat or slightly convex, lateral bead missing. Explanate lateral margin of pronotum with longitudinal and highly superficial microsculpture; reflexed lateral margin of elytron with rather superficial, isodiametric to very slightly longitudinal microsculpture, not contrastingly coarser than on disc.

Aedeagus with right paramere long (the annamita-subgroup) or short (the sulcicollis-subgroup). Internal sac of median lobe: PBL mostly tripartite or tetrapartite; $l v 3$ present except in one species.

COMMENTS. The group includes eight species arranged into two subgroups.

The annamita-subgroup is confined to the Dalat Plateau and defined by the combination of right paramere long, interval 10 present, submentum bisetose, endophallus with apical vesicles av1 to av4; mostly two well-developed PBR present, PBRd and PBRv.

The subgroup is further divided into two groupings with two species each. The combination of a circular pronotum; externally glabrous metatibiae; apical declivity of the prosternal process beaded along sides; sexually dimorphic proand metafemora (ventrobasal tubercle present in male); and the aedeagus type 2 (for details see 'Discussion') separates two sibling species, $P$. annamita and $P$. bidoupensis sp.n., from $P$. semiopacus sp.n. and $P$. abramovi sp.n. The latter two are distinctive in having median lobe of the aedeagus with dorso-apical tooth, the pronotum slightly more angulate, the metatibiae setose along outer margins, basal declivity of the prosternal process not beaded on sides, as well as pro- and metafemora lacking ventrobasal tubercles in both sexes.

The sulcicollis-subgroup contains the remaining four species with more northern distribution. They share the interval 10 missing, right paramere short, the submentum quadrisetose, the metatibiae setose along outer margin, pro- and metafemora not sexually dimorphic, and prosternal process not beaded on sides of the apical declivity. Besides, endophallus has av3 rudimentary or missing, presumably merged into the elongated $a v 2$, as well as $l v 2$ with internal sclerotized fold (except in one species) and PBR mostly missing or slightly convex.

Two northern species (P. sulcicollis sp.n. and P. anichkini sp.n.) differ from the remainder by frontal sulci being vestigial or obliterate ( $v s$. more or less deep), pronotal lateral groove very wide ( $v s$. narrow, as usual in the subgenus), and endophallic apical vesicle $a v 1$ missing (vs. present). The frontal sulci may reflect a meridional 'morphocline', being deepest in $P$. konchurang sp.n. from the northern Gia Lai Province and less so in $P$. ngokboci sp.n. from the eastern Kon Tum Province.

The suggested species relationships are as follows: $((P$. annamita $+P$. bidoupensis sp.n. $)+(P$. semiopacus sp.n. + $P$. abramovi sp.n. $))+((P$. konchurang sp.n. $+P$. ngokboci $)+$ (P. sulcicollis sp.n. and $P$. anichkini sp.n.)).

Worthy of note is endophallic PBL. It is tetrapartite in some members of the annamita-subgroup ( $P$. semiopacus sp.n.) and of the sulcicollis-subgroup (P. sulcicollis sp.n. and $P$. anichkini sp.n.), but tri- or bipartite in the rest, which suggests tetrapartite PBL as groundplan for the group.

1a. Pterostichus annamita annamita (Straneo, 1939) Figs 7, 61-62, 88-89.

Straneo, 1939: 121 (Feronia; Annam); 1984: 265 (part.). MATERIAL. Holotype $\sigma^{7}$ (MSNM) labelled: 'Annam, Langbian' [= Lang Bian Mt], 'Holotypus' [red], 'Feronia (subg. Alatilia) annamita, Holotypus! mihi [hw], det. Ing. Straneo', 'N.33' [hw]
Additional material. o' (SIEE), 'Vietnam, Khanh Hoa Province, Hon Ba Mt, 1300-1500 m, IV.2003, leg. M. Kalyakin; O'o (SIEE), same data except $\sim 1400 \mathrm{~m}$, leg. A. Borisenko; $2 \sigma^{\top} \sigma^{\top}$, same locality, except for 2006, leg. A. Anichkin.

REDESCRIPTION. BL 15.1-17.8 mm. Shiny black, elytra without or with indistinct purplish iridescence. Antennomeres 5-11 reddish along ridges, more widely apicad; palpi and tarsi slightly reddish; extreme apices of femora and tibiae very slightly reddish. Microsculpture highly superficial on head, superficial and moderately to strongly transverse on elytra, being sharper and very slightly longitudinal at bottom of elytral striae and on reflexed lateral margin; pronotal lateral margin with highly superficial and strongly longitudinal meshed microsculpture.

Head and, especially, neck incrassate, neck constriction very faint. Eyes slightly flattened, gena $1 / 3-2 / 5$ as long as eye. Frontal sulci very deep and strongly divergent, barely Sshaped, hardly less diverging anteriorly while barely curved at posterior end, almost reaching level of anterior supraocular seta. Submentum bisetose.

Pronotum (Fig. 7) circular, very large, hardly narrower than elytra, PW/PL 1.30-1.37 (mean 1.34, n=6), PW/HW $1.50-1.57$ (1.55); sides extended into base at no angle. Basal margin slightly concave. Apex slightly and evenly sinuate, finely beaded except in middle third. Apical angles slightly acute and a little porrect, with blunt tips. Lateral margin rather widely explanate, distinctly wider in basal two thirds than in front; lateral bead missing. Lateral groove sulcate yet narrow, disc subcarinate just inside; outer basal sulcus smooth S-shaped. Inner basal sulcus obsolete; basal fovea finely and moderately densely punctate (holotype) to impunctate. Disc very convex and smooth. Median line fine, reaching base, not quite reaching apex. Both transverse impressions, basal and apical, hardly traceable.

Elytra elliptic, EW/EL 1.44-1.53 (1.49), EW/PW 1.011.07 (1.04), broadest at about middle, rounded on sides. Humeral angle slightly obtuse. Striae deep and impunctate. Intervals convex, more so laterally and before apex, 1 st adjoining lateral bead apically, 7th, 5th and 3rd confluent successively apicad. Interval 8 as convex as 7 th, distinctly, albeit not very much, narrower than 7 th. Reflexed lateral margin broadened behind the middle, giving rise to a long interval 10. Parascutellar striole vestigial, short or very so. Discal seta $\mathrm{d} 2$ inserted 2/5-1/2 from apex, D2/EL 0.41-0.51 $(0.45, \mathrm{n}=6 \times 2)$. USS: $16-20$.

Underside. Apical declivity of prosternal process flat or slightly concave, with sides subcarinate or finely beaded, distinctly broader dorsally than ventrally. Entire abdomen finely beaded on sides. Mesepisternum, metepisternum, and sides of metaventrite moderately punctate to nearly smooth; basal abdominal sternites mostly vaguely punctate.

Legs: $t m 1-2$ with outer carina distinct, more (ta2) or less (ta3) blunt. In male, $f e l$ with a short oblique ventrobasal ridge looking like a tubercle in frontal view; $f e 3$ with a pointed tubercle near apex of $\operatorname{tr} 3$.

Aedeagus as in $P$. a. chuyangsin ssp.n. (Figs 37, 51): median lobe in middle third subequally wide in dorsal view, apex curved ventrad at a smooth and highly obtuse angle; apical lamella subtriangular in right view, without right dorsal tooth (in lateral view). Right paramere (Figs 61-62) long, arcuate, slightly broadened before apex in dorsal view, a little concave on left side apically. Everted and inflated internal sac (Figs 88-89) with large PBL and PBR. PBL bipartite due to $l v 3$ well-developed and almost separated from the remainder, $l v 1$ as a conical extension of PBL body dorsad; $l v 2$ missing (supposedly merged into $l v 1$ ) as is $l v i$ (minute $l v i$ present in 

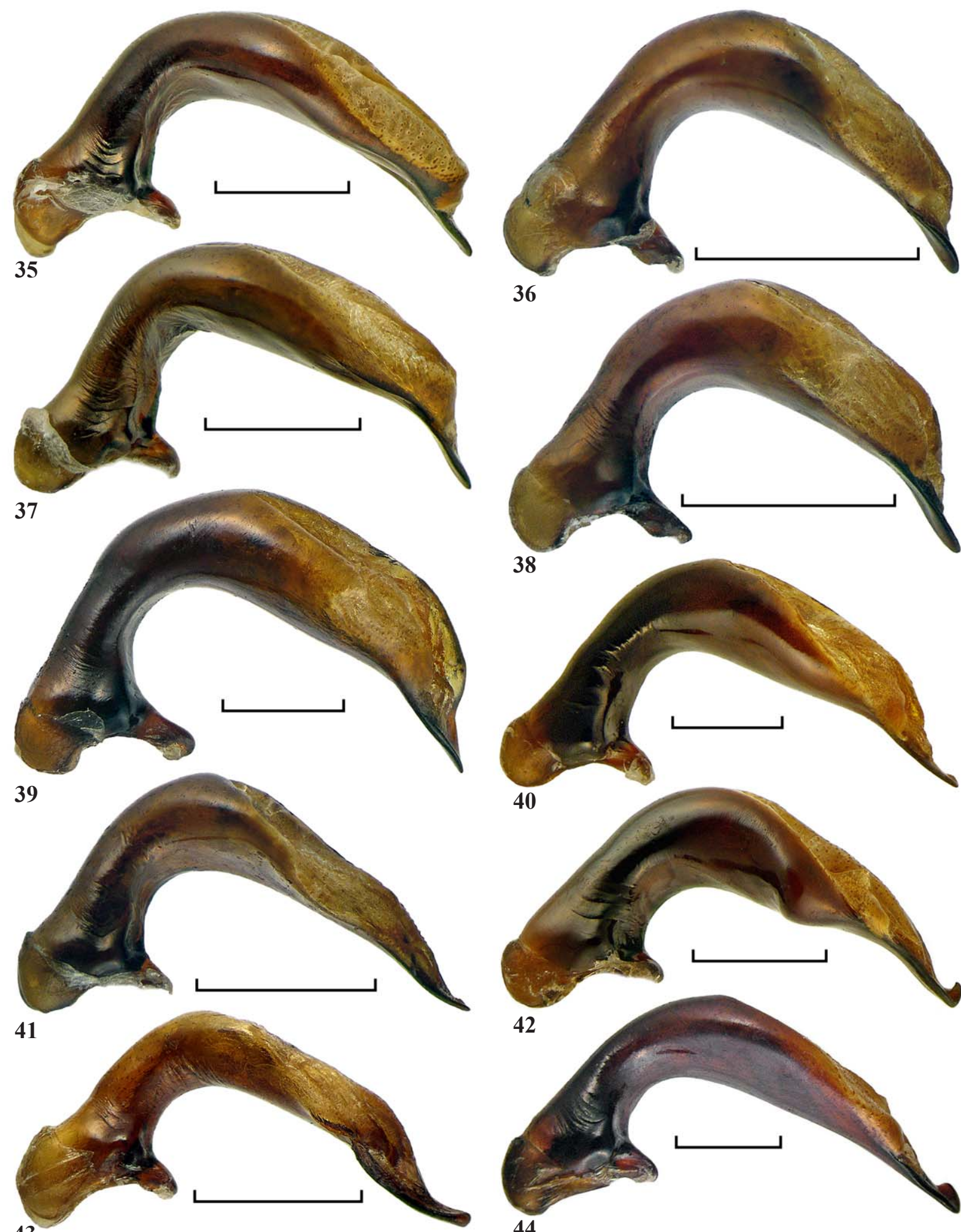

43

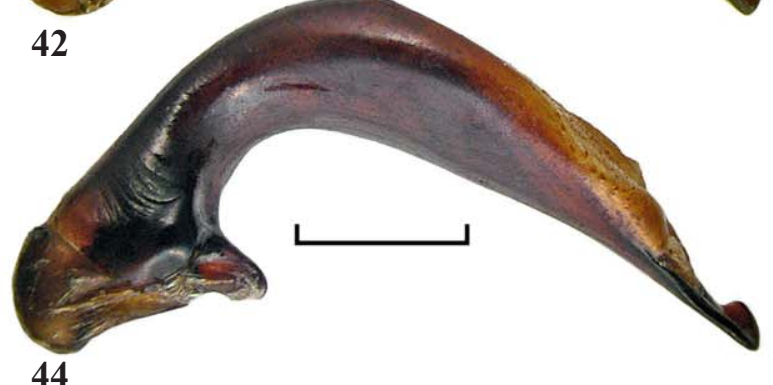

Figs 35-44. Median lobe of aedeagus, left aspect: 35 - Pterostichus bidoupensis sp.n.; 36 - P. ngoclinhensis sp.n.; 37 - P. annamita chuyangsin ssp.n.; $38-$ P. konplongensis sp.n.; $39-$ P. sulcicollis sp.n.; $40-$ P. semiopacus sp.n.; $41-$ P. chupanphan sp.n.; $42-$ P. abramovi sp.n.; 43 - P. kontumensis sp.n.; 44 - P. anichkini sp.n. Scale bars: $1 \mathrm{~mm}$.

Рис. 35-44. Средняя доля эдеагуса, вид слева: 35 - Pterostichus bidoupensis sp.n.; 36 - P. ngoclinhensis sp.n.; 37 - P. annamita chuyangsin ssp.n.; 38 - P. konplongensis sp.n.; $39-$ P. sulcicollis sp.n.; $40-$ P. semiopacus sp.n.; 41 - P. chupanphan sp.n.; $42-$ P. abramovi sp.n.; $43-P$. kontumensis sp.n.; $44-P$. anichkini sp.n. Масштаб: 1 мм. 
P. a. chuyangsin ssp.n.). PBRd and PBRv separate, former barely prominent, latter larger and projecting laterad. Apical vesicles (av1-4) subequally small. key.

DIAGNOSIS. See under P. bidoupensis sp.n., and in the

DISTRIBUTION. Three scattered localities in the Dalat Plateau, southern Vietnam. The nominate subspecies occurs in Mt. Hon Ba in addition to the type locality, Mt. Lang Biang near Dalat. Population(s) from the third locality represents a separate subspecies described below.

HABITATS AND HABITS. As for the subgenus.

COMMENTS. The pronotal basal foveae are minutely punctate in the holotype ( $v s$. impunctate in the other specimens examined). Since the two examined populations are widely separated, this difference may reflect the geographical variability.

\section{1b. Pterostichus annamita chuyangsin Fedorenko, ssp.n.}

Figs 19, 37, 51, 59-60, 90-91, 119.

MATERIAL. Holotype $\sigma^{\prime}$ (ZMMU) labelled: 'Vietnam, Dak Lak Prov.[ince], Chu Yang Sin Natn. Park, $12^{\circ} 23^{\prime} 48^{\prime \prime N} /$ $108^{\circ} 20^{\prime} 59^{\prime \prime E}$, Krong Kmar riv[er]., upper flow, $\mathrm{h}=1200-1650 \mathrm{~m}$, 30.III-14.IV.2012, D. Fedorenko leg.' Paratypes (SIEE, ZISP, ZMMU): $80^{7} 0^{7}, 12$ O9 , same data, as well as additional dates 21 .II1.IV.2013; $270^{7} \sigma^{7}, 20$ 우, same data except $108^{\circ} 21^{\prime} \mathrm{E}, \mathrm{h}=1000 \mathrm{~m}$, 30.III-14.IV.2012 and 21.III-1.IV.2013; $40^{7} \sigma^{7}, 4$ 오, same data, except for $12^{\circ} 22^{\prime} 40^{\prime \prime} \mathrm{N} 108^{\circ} 21^{\prime} 11^{\prime \prime E}, 1.5 \mathrm{~km} \mathrm{~W}$ [of ] Chu Pan Phan Mt, h=1650 m, 30.III-11.IV.2012; $60^{\top} \mathrm{O}^{7}$, 4우 same locality, except for $12^{\circ} 25^{\prime} 25^{\prime \prime} \mathrm{N} 108^{\circ} 21^{\prime} 53^{\prime \prime} \mathrm{E}, \mathrm{h}=970 \mathrm{~m}, 15-30 . \mathrm{V} .2014$.

DESCRIPTION. As compared with $P$. a. annamita: Body (Fig. 19), BL 13.2-15.7 mm. Frontal sulci from divergent to slightly S-shaped, parallel anteriorly, then curved outwards, and afterwards turned posteriad and slightly inwards. Neck constriction indistinct dorsally or extremely faint. Pronotum smaller, distinctly narrower than elytra and less wide relative to eyes, PW/PL 1.27-1.36 (mean 1.31, $\mathrm{n}=5$ ), PW/HW 1.451.53 (1.48). Apex often barely sinuate. EW/EL 1.44-1.56 (1.50), EW/PW 1.05-1.14 (1.10). Parascutellar striole from indistinct to moderately long. D2/EL $0.41-0.46(0.44, \mathrm{n}=5 \times 2)$. USS: $17-18$. Apical declivity of prosternal process nearly parallel-sided in ventral half, much broader dorsally.

Aedeagus (Figs 37, 51, 59-60, 90-91, 119) identical, but endophallic PBL indistinctly tripartite due to minute lvi present.

DIAGNOSIS. Distinctive from the nominate subspecies mainly in the body barely smaller, with the elytra distinctly purplish due to microsculpture highly superficial, consisting of very transverse meshes, almost transverse lines. Pronotum mostly with explanate lateral margin barely wider medially than apically and basally, and lateral groove extended into outer basal sulcus at no or hardly less than straight angle.

NAME. Refers to the Chu Yang Sin National Park, type locality of the species.

DISTRIBUTION. Two very close localities at the northern edge of the Dalat Plateau where the species occurs at 970 $1650 \mathrm{~m}$ elevation, being increasingly less common above $1200 \mathrm{~m}$.

HABITATS AND HABITS. As for the nominate subspecies.

2. Pterostichus bidoupensis Fedorenko, sp.n.

Figs 1-6, 11, 14-18, 20, 35, 49, 63-64, 92-93.

Straneo, 1984: 265 (part.)

MATERIAL. Holotype $\sigma^{7}$ (ZMMU) labelled: 'S[outh] Vietnam, Lam Dong Prov[ince]., Bi Doup - Nui Ba [Nature] Res[erve], $12^{\circ} 10^{\prime} 44^{\prime \prime N} 108^{\circ} 40^{\prime} 44^{\prime \prime} \mathrm{E}$, env. Long Lanh, $\mathrm{h}=1400-1600 \mathrm{~m}, 1-$ 2.IV.2008, leg. D. Fedorenko'. Paratypes (ZMMU, ZISP, SIEE): $180^{\top} O^{\top}, 15$ + 9 , same data, and additional dates between 29.III. and
11.VI.2008; $90^{\top} \mathrm{O}^{\top}, 13$ 우오, same data except $12^{\circ} 07^{\prime} \mathrm{N} 108^{\circ} 39^{\prime} 20^{\prime \prime} \mathrm{E}$ Bi Doup Mt., N[orthern] slope, $\mathrm{h}=1700-1900 \mathrm{~m}, 2-12 . I V .2008$ and $3-6 . V .2009 ; 20^{7} \sigma^{7}$, 6우, same data, except for $12^{\circ} 11^{\prime} \mathrm{N} / 108^{\circ} 42^{\prime} \mathrm{E}$, $\sim 4 \mathrm{~km}$ SSE of Hon Giao Mt., h=1500-1800 m, 2-23.IV.2008.

Additional material. \& (MSNM), labelled: 'DALAT ANNAM, III.IV.1924', 'Pterostichus annamita +, Str. [hw], det. S.L. Straneo 1978'.

DESCRIPTION. As for P. a. annamita except as follows. Body (Fig. 20), BL 13.5-16.4 mm. Shiny black, without distinct iridescence. Antennomeres 5-11 less paled.

Frontal sulci mostly straight, strongly divergent, not quite reaching the level of anterior supra-ocular seta.

Pronotum a bit smaller, PW/PL 1.26-1.35 (mean 1.30, n=5), PW/HW 1.41-1.47 (1.44). Explanate lateral margin subequally wide throughout; extension of lateral groove towards base (outer basal sulcus) barely sinuous. Basal fovea impunctate.

EW/EL 1.43-1.50 (1.47), EW/PW 1.12-1.18 (1.14). Elytral striae barely wider; interval 8 costate, much narrower than 7th. Parascutellar striole moderately long to missing, mostly very short or vestigial. D2/EL $0.41-0.51(0.46, \mathrm{n}=5 \times 2)$. USS: 17 , more rarely 18 .

Underside. Sides of apical declivity of prosternal process evenly concave between subequally wide dorsal and ventral margins. Abdominal sternites II and III without lateral bead.

Legs: $t a 2$ and $t a 3$ usually with slightly more distinct outer carinae.

Aedeagus (Figs 35, 49, 63-64, 92-93): median lobe in dorsal view slightly broadened at middle of left margin; apical lamella trapezoidal, with widely rounded apical angles. Right paramere long and nearly geniculate, i.e., with a distinct, slightly obtuse, angle between basal and apical parts. Everted and inflated internal sac: PBL large, conical anterodorsally $(l v 1)$, indistinctly tripartite owing to $l v i$ missing and $l v 2$ hardly traceable as a convexity just distal to $l v 1$. PBR extensive yet only slightly projecting.

DIAGNOSIS. Very similar to the previous species, differing chiefly in structure of the aedeagus. The combination of the black body, not laterally beaded abdominal sternite II and differently shaped apical declivity of the prosternal process differentiates between females of $P$. bidoupensis and $P$. annamita.

NAME. Refers to the type locality of this species, the $\mathrm{Bi}$ Doup - Nui Ba Nature Reserve, including Mt. Bi Doup.

DISTRIBUTION. The Dalat Plateau between Mt. Hon Giao and Mt. Bi Doup; the listed record from Da Lat needs confirmation.

HABITATS AND HABITS. A mesophilous species common in monsoon forests at $1400-1800 \mathrm{~m}$ elevation. It also shares certain habitats with $P$. dalatensis sp.n., but avoids wet places the latter species prefers.

COMMENTS. Straneo (1984) reported P. annamita from Da Lat based on two female specimens distinctive from the male holotype in no other character than the pronotal lateral margin subequally wide throughout ( $v s$. markedly broadened basad). Based on several examined photographs of one of these females, I consider it to belong to P. bidoupensis sp.n., which suggests also that $P$. bidoupensis sp.n. and $P$. $a$. annamita may be sympatric in the environs of Da Lat.

\section{Pterostichus abramovi Fedorenko, sp.n.} Figs 22, 42, 50, 65-67, 94-95, 117.

MATERIAL. Holotype $0^{7}$ (ZMMU) labelled: 'Vietnam, Dak Lak Prov [ince]., Chu Yang Sin Nat[io]n[al]. Park, 12 $22^{\prime} 40^{\prime \prime N}$ $108^{\circ} 21^{\prime} 11^{\prime \prime E}, 1.5 \mathrm{~km} \mathrm{~W}$ [of ] Chu Pan Phan Mt, h=1650 m, 30.III11.IV.2012. Paratypes (SIEE, ZISP): $20^{7} \sigma^{7}, 2+0$, same data; $40^{7} \sigma^{7}$, 3 우, same data, except for $12^{\circ} 22^{\prime} 36^{\prime \prime} \mathrm{N} 108^{\circ} 21^{\prime} 13^{\prime \prime} \mathrm{E}, 19$.III2.IV.2013; $\sigma^{7}$, same data, except for $12^{\circ} 24^{\prime} 32^{\prime \prime} \mathrm{N} 108^{\circ} 23^{\prime} 17^{\prime \prime} \mathrm{E}$ $\sim 3 \mathrm{~km} \mathrm{~W}$ [of ] Chu Yang Sin Mt, h=1500-1600 m, 15-30.V.2014. 

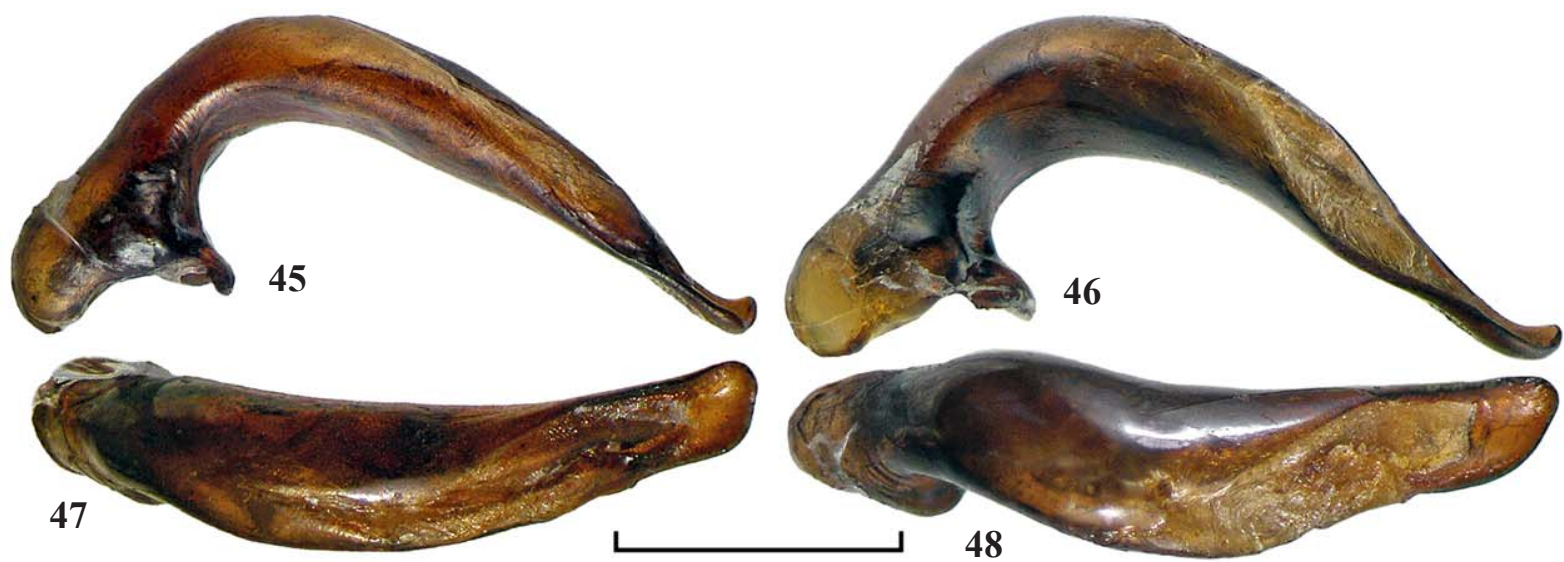

47
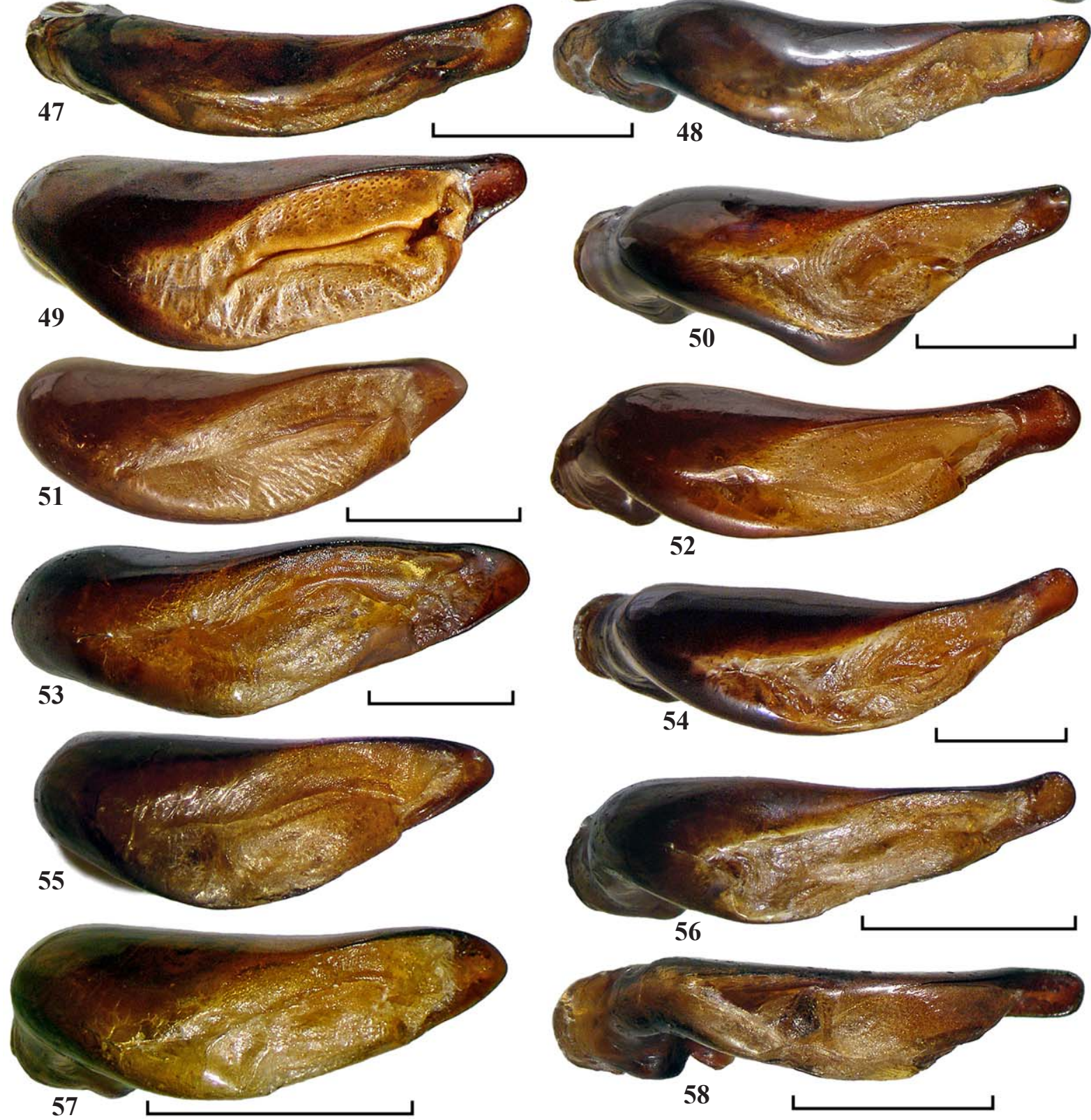

52
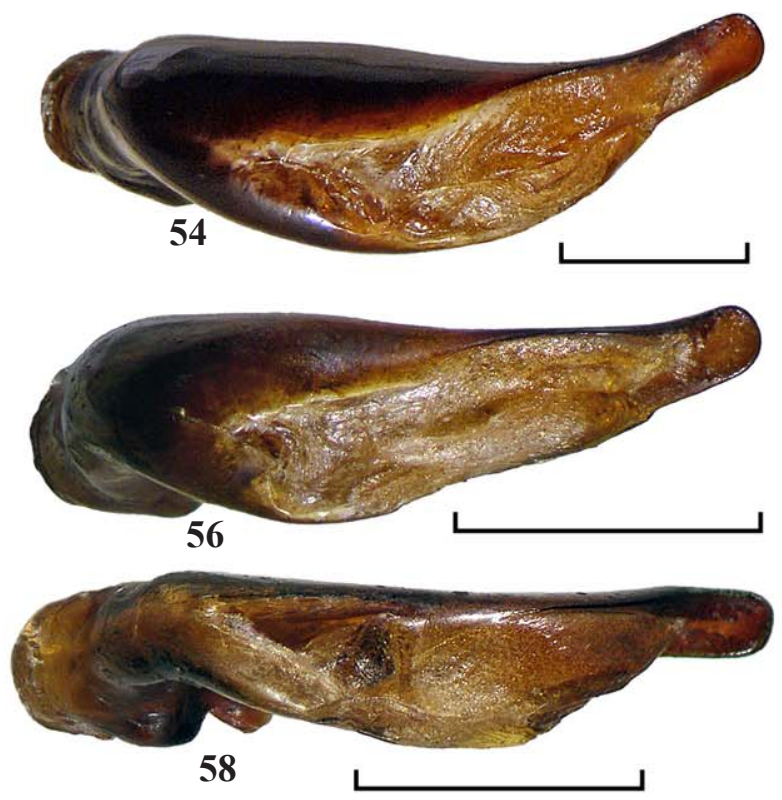

Figs 45-58. Median lobe of aedeagus, left $(45,46)$ and dorsal $(47-58)$ aspect: 45,47 - Pterostichus honbaensis sp.n.; 46, 48 P. dalatensis sp.n.; $49-$ P. bidoupensis sp.n.; $50-$ P. abramovi sp.n.; $51-$ P. annamita chuyangsin ssp.n.; 52 - P. anichkini sp.n.; $53-$ P. sulcicollis sp.n.; $54-$ P. semiopacus sp.n.; $55-$ P. ngoclinhensis sp.n.; $56-$ P. chupanphan sp.n.; 57 - P. konplongensis sp.n.; $58-$ P. kontumensis sp.n. Scale bar: $1 \mathrm{~mm}$.

Рис. 45-58. Средняя доля эдеагуса, вид слева $(45,46)$ и сверху (47-58): 45, 47 - Pterostichus honbaensis sp.n.; 46, 48 P. dalatensis sp.n.; 49 - P. bidoupensis sp.n.; 50 - P. abramovi sp.n.; 51 - P. annamita chuyangsin ssp.n.; 52 - P. anichkini sp.n.; 53 P. sulcicollis sp.n.; 54 - P. semiopacus sp.n.; 55 - P. ngoclinhensis sp.n.; 56 - P. chupanphan sp.n.; 57 - P. konplongensis sp.n.; 58 P. kontumensis sp.n. Масштаб: 1 мм. 
DESCRIPTION. As for P. annamita, except as follows: Body (Fig. 22), BL 13-15.5 mm. Shiny black, with nearly indistinct purplish iridescence in female.

Head, including neck, slightly less incrassate. Frontal sulci very deep, strongly divergent, not quite reaching the level of anterior supra-ocular seta. Neck constriction indistinct.

Pronotum almost circular, PW/PL 1.29-1.37 (mean 1.32, $\mathrm{n}=5)$, PW/HW 1.52-1.59 (1.55), with basal angles very widely rounded yet traceable. Explanate lateral margin moderately wide anteriorly, much broader behind the middle. Inner basal sulcus shallow, converging slightly apicad. Basal fovea impunctate. Both transverse impressions, basal and apical, missing, sometimes the latter hardly traceable.

Elytral base concealed with base of pronotum, EW/EL 1.48-1.53 (1.50), EW/PW 1.05-1.15 (1.09). Striae impunctate, deep yet very fine, with one row of microsculpticells at bottom. Interval 8 costate, much narrower than 7th. Parascutellar striole absent, sometimes very short. D2/EL 0.43 $0.49(0.46, \mathrm{n}=5 \times 2)$. USS: $17-19$, mostly adjoining or situated in stria 8 .

Underside. Apical declivity of prosternal process slightly convex, neither edged nor beaded laterally.

Legs: ti3 externally with $1-4$, mostly two, setae; sometimes the setae absent unilaterally; $f e 1$ and $f e 3$ similar in both sexes.

Aedeagus (Figs 42, 50, 65-67): median lobe in dorsal view triangular. Apical lamella rhomboidal, concave dorsally, with a large right dorso-apical hook. Right paramere as in $P$. bidoupensis sp.n., yet more clavate in dorsal view. Everted and inflated internal sac (Figs 94-95,117): PBL fairly small, distinctly tripartite, with three contiguous apical lobes, median lobe (lv2) being a little larger than lateral ones (lvl and $l v i)$. PBRd very large and contiguous to small PBRv.

DIAGNOSIS. Distinctive from very similar $P$. annamita in having pronotum slightly broader basally, with basal angles very widely rounded yet traceable; $t i 3$ externally setose; lateral bead absent from sternite II and anterior three quarters of III; $f e l$ and $f e 3$ similar in the sexes; aedeagus different, including right paramere.

NAME. Given after Dr. Alexei V. Abramov, a mammologist, my good friend and companion during trips to Vietnam, who helped me collect this and many other carabids.

DISTRIBUTION. Two close localities at the northern edge of the Dalat Plateau, Mt. Chu Pan Phan and Mt. Chu Yang Sin, where it occurs at $1500-1650$ m elevation.

HABITATS AND HABITS. As for the subgenus.

\section{Pterostichus semiopacus Fedorenko, sp.n.} Figs 21, 40, 54, 70-71, 96-97.

MATERIAL. Holotype O' (ZMMU) labelled: 'S[outh] Vietnam, Lam Dong Prov[ince]., Bi Doup - Nui Ba [Nature] Res[erve], $12^{\circ} 07^{\prime} \mathrm{N} 108^{\circ} 39^{\prime} 20^{\prime \prime E}, \mathrm{Bi}$ Doup Mt., N[orthern] slope, $\mathrm{h}=1700$ 1900 m, 15-16.IV.2008, leg. D. Fedorenko'. Paratypes (SIEE) $2 \sigma^{7} \sigma^{7}$, same data, and additional date 19-22. IV.2008; $\odot^{7},+$, same data, except for 3-9.V.2009.

DESCRIPTION. Body (Fig. 21), BL 17.3-19.2 mm. Same coloured and microsculptured as $P$. annamita, except for elytra dull from coarse isodiametric microsculpture, and head with superficial yet distinct isodiametric microsculpture.

Head large, with a thick neck. Eyes convex yet fairly small, gena 1/3-1/2 as long as eye. Frontal sulci deep, straight, strongly divergent, almost reaching level of anterior supraocular seta, mostly curved very slightly inwards at the extreme posterior end. Neck constriction indistinct or almost so. Supra-ocular groove very deep, more so posteriorly. Submentum bisetose.
Pronotum subquadrate, rather narrow, less than a third broader than head (vs. $2 / 5-3 / 5$ in the other species of the group), PW/PL 1.23-1.31 (mean 1.28, n=5), PW/HW 1.261.32 (1.29), poorly rounded and thence almost parallelsided in apical half, more rounded behind, with basal angles rounded yet traceable. Base gently sinuate at middle; apex nearly truncate, apical bead very fine and obliterate in middle 1/3-2/4. Apical angles narrowly rounded, very slightly or not projecting. Explanate lateral margin rather narrow, somewhat bead-like in apical half, increasingly wider basad, moderately wide in basal two fifths, expanded slightly inwards in basal quarter. Lateral groove very widely sulcate, disc edged just inside; outer basal sulcus S-shaped. Inner basal sulci rather shallow to moderately deep, diverging fapicad, parallel anterioly. Basal foveae smooth. Disc convex and smooth. Median line fine, reaching base, not quite reaching apex. Both transverse impressions, basal and apical, obliterate.

Elytra as in P. annamita, EW/EL 1.52-1.55 (1.53), EW/ PW 1.11-1.18 (1.14); sides rounded at shoulders, then straight to indistinctly concave, diverging in basal $1 / 3-2 / 5$. Striae deep impunctate. Interval 8 costate, much narrower than 7 th. Interval 10 very long, running on apical 3/4. Parascutellar striole short to moderately long. Discal seta $\mathrm{d} 2$ distinctly behind the middle, D2/EL 0.37-0.45 (0.40, $\mathrm{n}=5 \times 2)$. USS: $17-20$.

Underside. Apical declivity of prosternal process flat or subconvex, subequally wide dorsally and ventrally; sides evenly sinuate, neither edged nor beaded. Abdomen finely beaded on sides. Mesepisternum, metepisternum and sides of metaventrite finely and sparsely punctate to nearly impunctate, abdominal sternites II, III and usually also IV finely and moderately densely punctate along sides.

Legs: ta $2(t m 1-2)$ and $t a 3(t m 1-3)$ with outer carina mostly blunt to vestigial yet traceable; $f e 3$ bisetose, distal seta being distinctly shorter than proximal one to (rarely) vestigial unilaterally; ti3 externally with $1-3$ setae.

Aedeagus (Figs 40, 54, 70-71, 96-97): median lobe in dorsal view evenly convex at left margin, apex long and parallel-sided; terminal lamella square, apically rounded in dorsal view, with a small rounded dorso-apical tooth (traceable in right view). Right paramere similr to that of P. abramovi sp.n. but a very slender apical part. Everted and inflated internal sac: PBL large tetrapartite, with $l v 2$ being largest $l v$ widely separated from fairly small $l v i$. PBRd barely larger than and contiguous to PBRv.

DIAGNOSIS. Distinctive in having a rather large body, with elytra dull from coarse isodiametric microsculpture; pronotum nearly parallel-sided in apical half, with basal angles rounded yet traceable and lateral groove widely sulcate; elytral interval 8 costate and very narrow. Bisetose $f e 3$ and very long elytral interval 10 are unique characters in the subgenus.

NAME. Refers to dull elytra, combined with shiny forebody dorsum.

DISTRIBUTION. Mt. Bi Doup, the Dalat Plateau. A substitute for P. bidoupensis sp.n. at higher altitudes $(1900 \mathrm{~m})$.

HABITATS AND HABITS. As for P. bidoupensis sp.n.

\section{Pterostichus sulcicollis Fedorenko, sp.n.} Figs 25, 39, 53, 69, 102-103.

MATERIAL. Holotype $\sigma^{7}$ (ZMMU) labelled: 'Vietnam, Kon Tum Prov[ince], $2-3 \mathrm{~km} \mathrm{~W}$ of Ngoc Linh Mt., $15^{\circ} 05^{\prime} \mathrm{N}, 107^{\circ} 57^{\prime} \mathrm{E}$, $\mathrm{h}=1600-2150 \mathrm{~m}$, pitfall traps, 19.III-9.IV.2006, leg. A. Anichkin'. Paratypes $40^{7} O^{7}$, 4 우 (SIEE), same data; $30^{7} O^{7}$ (ZISP) same data except '...Central Highlands, $2-3 \mathrm{~km}$ W of Ngoc Linh Mt., ..., 1700-1900 m, 5.III-14.IV.2004, A.V. Abramov’. 


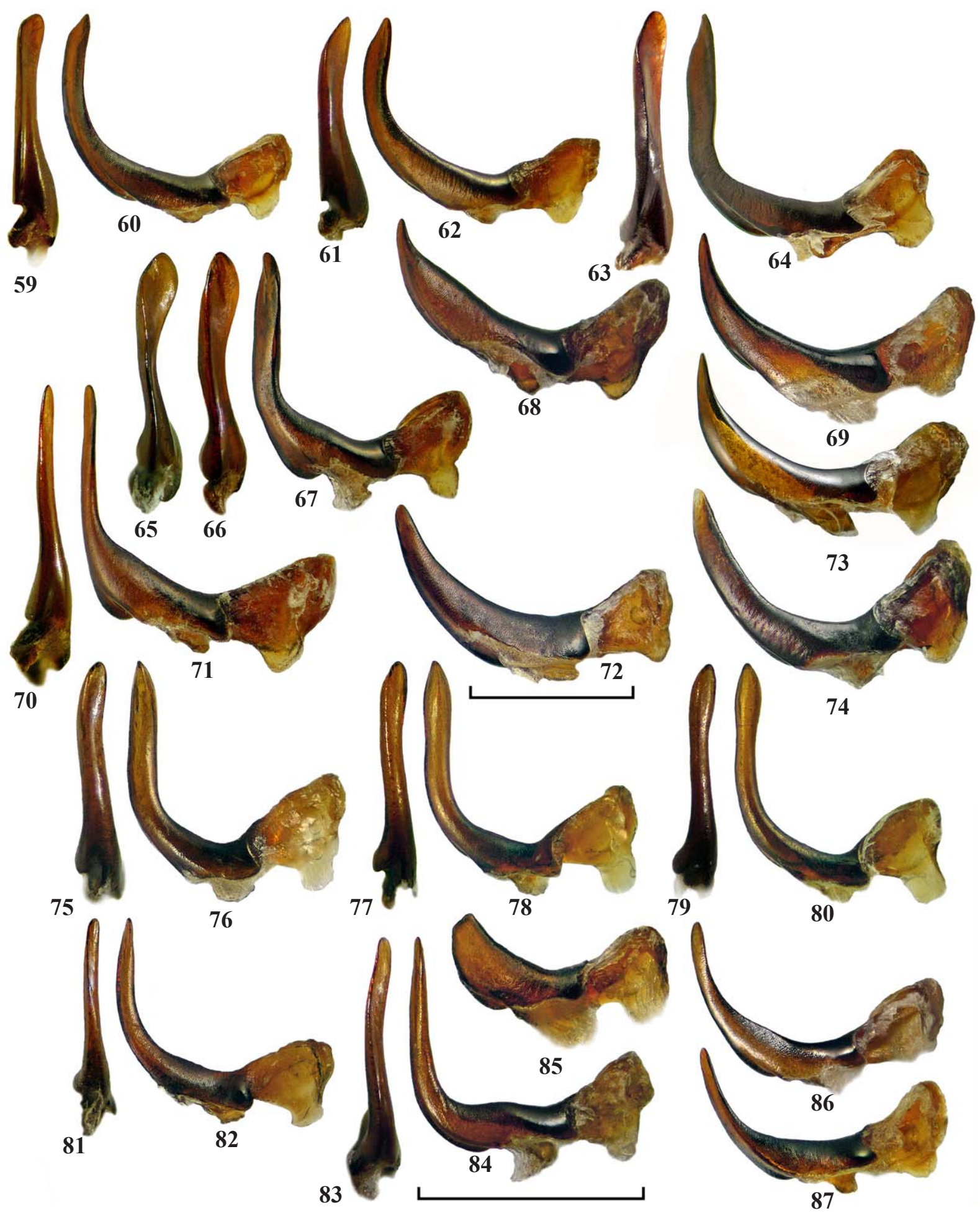

Figs 59-87. Right paramere: 59-60 - Pterostichus annamita chuyangsin ssp.n.; 61-62 - P. annamita; 63-64 - P. bidoupensis sp.n.; 65-67 - P. abramovi sp.n.; $68-$ P. konchurang sp.n.; $69-$ P. sulcicollis sp.n.; 70-71 - P. semiopacus sp.n.; 72 - P. anichkini sp.n.; 73 - P. ngokboci sp.n.; $74-$ P. gialaiensis sp.n.; 75-80 - P. dalatensis sp.n.; 81-82 - P. honbaensis sp.n.; 83-84 - P. chupanphan sp.n.; 85 - P. kontumensis sp.n.; $86-P$. ngoclinhensis sp.n.; 87 - P. konplongensis sp.n.; 59, 61, 63, 65-67, 70, 75, 77, 79, 81, 83 dorsal aspect; 60, 62, 64, 67-69, 71-74, 76, 78, 80, 82, 84-87 - left aspect. Scale bar: $1 \mathrm{~mm}$.

Рис. 59-87. Правая парамера: 59-60 - Pterostichus annamita chuyangsin ssp.n.; 61-62 - P. annamita; 63-64 - P. bidoupensis sp.n.; 65-67 - P. abramovi sp.n.; $68-P$. konchurang sp.n.; $69-$ P. sulcicollis sp.n.; 70-71 - P. semiopacus sp.n.; $72-P$. anichkini sp.n.; $73-P$. ngokboci sp.n.; $74-P$. gialaiensis sp.n.; 75-80 - P. dalatensis sp.n.; 81-82 - P. honbaensis sp.n.; 83-84 P. chupanphan sp.n.; 85 - P. kontumensis sp.n.; 86 - P. ngoclinhensis sp.n.; 87 - P. konplongensis sp.n.; 59, 61, 63, 65-67, 70, 75, 77, 79, 81, 83 - дорзально; 60, 62, 64, 67-69, 71-74, 76, 78, 80, 82, 84-87- слева. Масштаб: 1 мм. 
DESCRIPTION. Body (Fig. 25), BL 16.4-18.5 mm. Shiny black, without iridescence, otherwise same coloured as P. annamita. Microsculpture superficial yet distinct on head, isodiametric and superficial on elytra.

Head fairly large, eyes convex and small, gena about half as long as eye. Frontal sulci very shallow to nearly indistinct, mostly straight, strongly divergent, short, not reaching level of anterior supra-ocular seta. Neck constriction indistinct dorsally. Submentum quadrisetose.

Pronotum as in P. abramovi sp.n., except as follows: PW/PL 1.35-1.43 (mean 1.39, n=5), PW/HW 1.39-1.47 (1.44). Apex evenly sinuate; apical angles slightly acute, with narrowly rounded tip. Explanate lateral margin mostly convex, lateral edge very gently corrugated. Lateral groove sulcate, deep, very wide, as wide as explanate lateral margin near anterolateral seta; disc sharp-edged just inside. Outer basal sulcus C-shaped, i.e., curved basally outside, instead of inside. Inner basal sulci diverging slightly apicad or parallel anteriorly, shallow, basally very shallow to obliterate.

Elytra elliptic, EW/EL 1.47-1.54 (1.50), EW/PW 1.111.18 (1.14). Humeral angle slightly obtuse. Striae deep impunctate. Intervals convex, more so laterally and before apex. Interval 8 costate to subcarinate, much narrower than 7 th. Reflexed lateral margin narrow throughout, without interval 10. Parascutellar striole short to missing, mostly very short. Discal seta inserted just medially, D2/EL 0.48-0.54 (0.52, $\mathrm{n}=5 \times 2$ ). USS: $20-22$.

Underside. Apical declivity of prosternal process flat or slightly concave, sharply edged to indistinctly beaded on sides. Sides of abdomen rather finely beaded anteriorly, with lateral bead obliterate on basal half to entire sternite II. Punctation varying greatly from indistinct to moderate and fairly dense on mesepisternum, metepisternum and sides of metaventrite; abdominal sternite II mostly densely rugulosepunctate along basal margin.

Legs: ti3 externally with $1-3$, mostly two, setae; outer carinae blunt to distinct on $\operatorname{ta} 2(\operatorname{tm} 1-2)$, blunt to obsolete on ta3 (tm1-3).

Aedeagus (Figs 39, 53,69) similar to tht of P. annamita, except for falcate and short right paramere. Everted and inflated internal sac (Figs 102-103) with tripartite PBL: lv2 large invaginate due to internal fold being well-developed; lv3 small; lvi distinct (perhaps PBL is tetrapartite). PBR missing. There present three apical vesicles: elongate av2, very small av3 close to its apex, and well-developed av4.

DIAGNOSIS. Most similar to P. abramovi sp.n. Distinguishable among larger species chiefly by the following character combination: frontal sulci obsolete; elytra with isodiametric microsculpture, without interval 10; pronotal lateral groove widely sulcate, as wide as explanate lateral margin at anterolateral seta; $f e 3$ bisetose; ti3 externally setose. Right paramere moderately long.

NAME. Refers to the deep and widely sulcate lateral groove of the pronotum.

DISTRIBUTION. Endemic to Mt. Ngoc Linh in Central Vietnam; all specimen taken at 1700-1900 m elevation.

HABITATS AND HABITS. As described for the subgenus.

\section{Pterostichus anichkini Fedorenko, sp.n.}

Figs 26, 44, 52, 72, 104-105.

MATERIAL. Holotype $\sigma^{7}$ (ZMMU) with label: 'Vietnam, Kon Tum Prov[ince], 2-3 km W of Ngoc Linh Mt., $15^{\circ} 05^{\prime} \mathrm{N}, 107^{\circ} 57^{\prime} \mathrm{E}$ $\mathrm{h}=1600-2150 \mathrm{~m}$, pitfall traps, 19.III-9.IV.2006, leg. A. Anichkin' Paratypes $\sigma^{7}, 3$, 3 (SIEE), same data; $20^{7} \sigma^{7}$ (ZISP) same data, except for '..., Central Highlands, $2-3 \mathrm{~km} \mathrm{~W}$ of Ngoc Linh Mt., ..., 1700-1900 m, 5.III-14.IV.2004, A.V. Abramov'.
DESCRIPTION. As for $P$. sulcicollis sp.n. except as follows. Body slender (Fig. 26), BL 17.8-19.4 mm. Elytral Microsculpture sexually dimorphic, bing superficial, moderately to strongly transverse in male $v s$. isodiametric in female; elytral striae behind the middle (especially where broadened before apex) with coarse isodiametric microsculpture.

Frontal sulci obliterate.

Pronotum subquadrate and less transverse, PW/PL 1.291.31 (mean 1.30, n=5), PW/HW 1.39-1.43 (1.41), with sides rather poorly rounded in apical half and very so behind the middle. Apical margin less concave. Lateral edge smooth, without corrugation. Lateral groove slightly narrower and more shallow, leaving disc laterally sharp-edged in middle third only. Inner basal sulci diverging slightly apicad, obliterate basally.

Elytra longer, EW/EL 1.57-1.66 (1.62), EW/PW 1.121.17 (1.15). Humeral angle slightly obtuse. Striae deep and impunctate. Intervals 3, 5 and 7 often slightly broader than adjacent ones; 3rd, 7th and sometimes 5th sharply carinate before apex; only 3 rd and 7 th confluent apically. Interval 8 carinate throughout. Parascutellar striole mostly missing to very short. D2/EL $0.49-0.56(0.53, \mathrm{n}=5 \times 2)$. USS: $23-24$.

Underside smooth. Apical declivity of prosternal process flat or slightly concave, sharply edged to indistinctly beaded on sides.

Legs: $t i 3$ externally with 3-5 setae; tarsi with outer carinae conspicuous $(\mathrm{tm} 1-2, \mathrm{ta} 2)$ or blunt $(\mathrm{tm} 1-3, \mathrm{ta} 3)$.

Aedeagus (Figs 44, 52, 72) nearly as in P. semiopacus sp.n., except as follows: Apical lamella in dorsal view much broader, very gently broadened apicad, widely rounded at tip, concave dorsally, with a large right dorso-apical tooth. Right paramere short. Everted and inflated endophallus (Figs 104105): PBL bipartite, basally bulbous, with small $l v 3$; and nearly indistinct $l v 1$ dorsally. PBRv large prominent. Two large apical vesicles present, $a v 4$ and $a v 2$, the latter being ventrally extended into a sclerotized stripe.

DIAGNOSIS. See description of the species and the key.

NAME. Given after Alexander E. Anichkin (Ioshkar Ola), a soil zoologist, my good friend and colleague, collector of this species.

DISTRIBUTION. Endemic to Mt. Ngoc Linh in Central Vietnam; occurring at 1700-1900 m elevation.

HABITATS AND HABITS. As for the subgenus.

\section{Pterostichus ngokboci Fedorenko, sp.n.} Figs 24, 73, 98-99.

MATERIAL. Holotype $\sigma^{7}$ (ZMMU): 'Vietnam, Kon Tum Prov[ince]., Kon Plong Distr[ict]., $14^{\circ} 45^{\prime} \mathrm{N} 108^{\circ} 17^{\prime} 51^{\prime \prime E}$, env. ngok Boc I Mt., $h=1300-1400 \mathrm{~m}, 8-10$. VI.2016, D. Fedorenko leg.' Paratypes (SIEE): + , same data; 3 우, same data, except for $14^{\circ} 45^{\prime} \mathrm{N} 108^{\circ} 18^{\prime} 10^{\prime \prime} \mathrm{E}, \mathrm{h}=1200-1300 \mathrm{~m}$ 8-23.IV.2015.

DESCRIPTION. As for P. sulcicollis sp.n., except as follows. Body (Fig. 24), BL 17.9-18.5 mm. Elytral microsculpture slightly to moderately transverse.

Head medium-sized. Frontal sulci fine and fairly shallow, barely deeper just behind clypeus, much shallower to obsolete behind, evenly curved towards anterior supra-ocular seta, disappearing much before the level of the seta.

Pronotum nearly circular, slightly less transverse, $\mathrm{PW} /$ PL 1.25-1.31 (mean 1.28, n=4), PW/HW 1.52-1.59 (1.55), evenly rounded on sides. Apex evenly and rather shallowly sinuate; apical angles slightly blunted. Lateral margin flat, with smooth lateral edge; lateral groove narrow; disc not or barely edged just inside the groove. Outer basal sulcus Cshaped, almost straight, not quite reaching base. Inner basal sulci shallow, diverging slightly apicad, obliterate basally, barely deeper anteriorly. 
Elytra elliptic, longer, EW/EL 1.55-1.56 (1.56), EW/PW 1.06-1.11 (1.08), almost parallel-sided in middle third. Parascutellar striole short to missing, mostly very short. D2/EL $0.47-0.50(0.49, \mathrm{n}=4 \times 2)$. USS: $20-22$.
Underside. Apical declivity of prosternal process very gently concave, with sides almost indistinctly beaded. Abdomen entirely beaded along sides. Mesepisternum, sides of metaventrite and usually metepisternum moderately and rath-
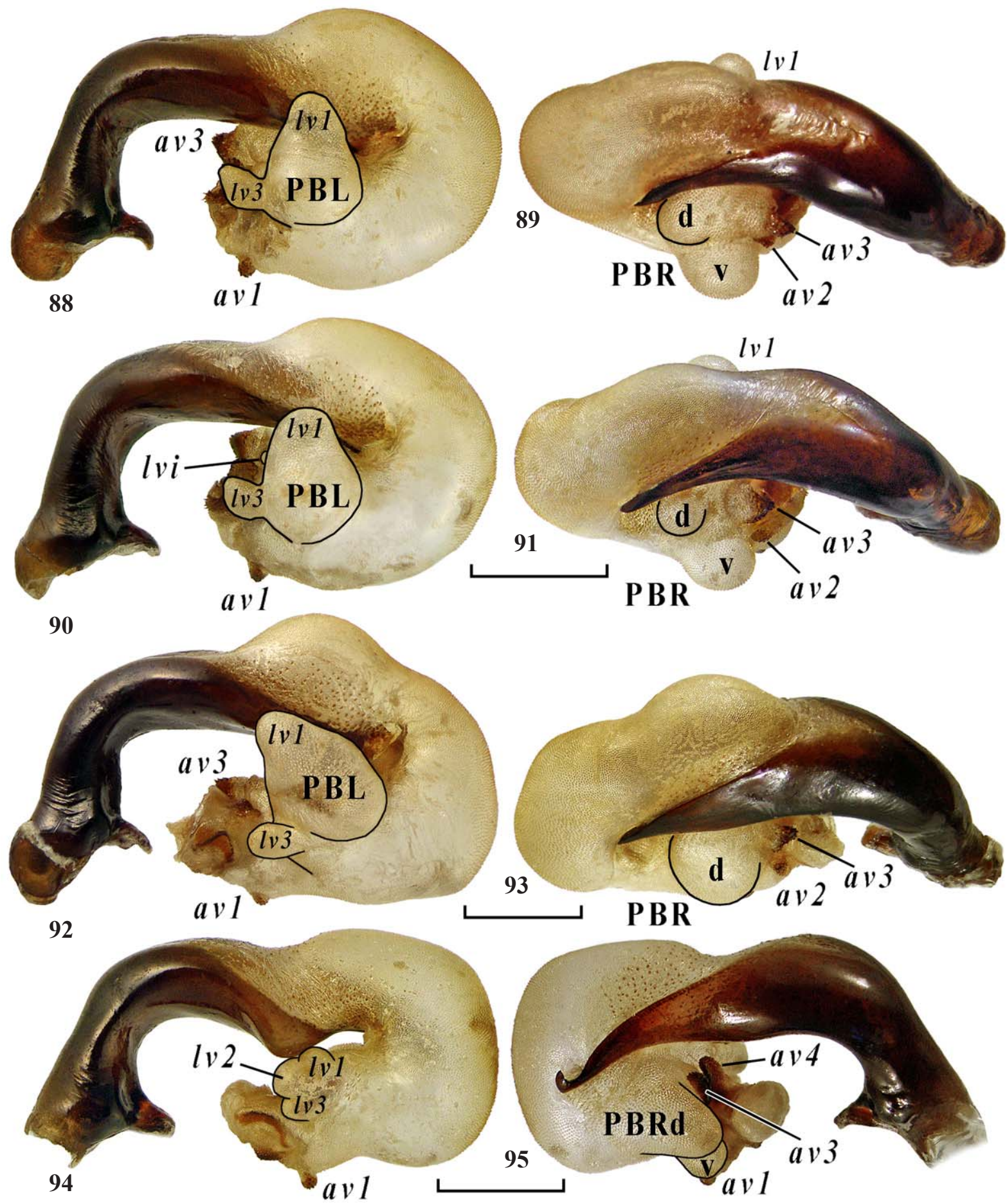

Figs 88-95. Everted and inflated internal sac of aedeagus: 88-89- Pterostichus annamita; 90-91 - P. annamita chuyangsin ssp.n.; 92-93 - P. bidoupensis sp.n.; 94-95 — P. abramovi sp.n.; 88, 90, 92, 94 — left aspect; 89, 91 — left dorsolateral aspect; 93, 95 — right aspect. Scale bar: $1 \mathrm{~mm}$. Abbreviations as in Figs 12-13.

Рис. 88-95. Вывернутый и надутый внутренний мешок эдеагуса: 88-89 - Pterostichus annamita; 90-91 - P. annamita chuyangsin ssp.n.; 92-93 - P. bidoupensis sp.n.; 94-95 - P. abramovi sp.n.; 88, 90, 92, 94 - слева; 89, 91 - слева и сверху; 93, 95 — справа. Масштаб: 1 мм. Обозначения как на рис. 12-13. 
er densely punctate; abdominal sternite II mostly densely punctate along base, sternite III with very shallow to indistinct punctures.

Legs: ti3 externally with $2-3$ setae; $t m 1-2$ with outer carinae distinct to obsolete (ta2) or totally reduced (ta3), sometimes $t a 3$ with hardly traceable lateroventral sulcus.

Aedeagus (Figs 73, 98-99) very similar. Everted and inflated endophallus: PBL tetrapartite, bifid apically $(l v l$ and $l v 2$ ), with small $l v i$ near these two, and $l v 3$ at base. PBR missing. Three, fairly large, apical vesicles present, $a v 2, a v 4$, and a vesicle being either $a v 1$, shifted to the right side, or novelty.

DIAGNOSIS. Similr to $P$. sulcicollis sp.n., except as follos: body barely slenderer; frontal sulci curved outside and slightly deeper; pronotal lateral groove narrow; and aedeagus ditinctive.

NAME. Toponymic as if it were patronymic; refers to the type locality, Mt. Ngok Boc.

DISTRIBUTION. The type locality only; all specimens taken by pitfall traps at 1250-1400 m elevations.

HABITATS AND HABITS. As for the subgenus.

\section{Pterostichus konchurang Fedorenko, sp.n.} Figs 23, 68, 100-101.

MATERIAL. Holotype $0^{7}$ (ZMMU) and paratypes $29 \odot$ (SIEE) labelled: 'Vietnam, Gia Lai Province, $\sim 50 \mathrm{~km} \mathrm{~N}$ of An Khe, Kon Chu Rang Nat[ure]. Reserv[e]., 14 $4^{\circ} 31^{\prime} \mathrm{N} 108^{\circ} 32^{\prime} \mathrm{E}, \mathrm{h}=1000-1040 \mathrm{~m}$, 24.V-2.VI.2016, D. Fedorenko leg.'

DESCRIPTION. As for P. ngokboci sp.n., except as follows: Body (Fig. 23), BL 20.4-22.3 mm. Elytral microsculpture very transverse.

Eyes barely flatter, genae indistinctly longer. Frontal sulci deep, from divergent and slightly S-shaped, nearly straight, to parallel-sided behind clypeus and then curved posterolaterad, not quite reaching the level of anterior supraocular seta.

PW/PL 1.31-1.34 (mean 1.33, n=3), PW/HW 1.49-1.55 (1.51); basal angles obtuse and rather narrowly rounded. Disc not laterally edged.

Elytra slightly and evenly rounded on sides, EW/EL 1.471.53 (1.49), EW/PW 1.08-1.10 (1.09). Intervals 3 and 7 confluent apically or (in one paratype) 7th, 5th and 3rd successively confluent apicad. Parascutellar striole mostly short or very so. D2/EL $0.46-0.49(0.48, n=3 \times 2)$. USS: $24-25$.

Underside. Apical declivity of prosternal process varying from gently concave and finely beaded along sides to flat, with no bead. Abdominal sternite II without lateral bead. Mesepisternum very finely and mostly rather sparsely punctate; metepisternum and sides of metaventrite finely and sparsely punctate to smooth; abdominal sternite II with a group of fine punctures behind base, sternite III smooth.

Legs: $t i 3$ externally trisetose.

Aedeagus (Figs 68, 100-101) similar, except for right paramere straight in apical half of ventral margin but tip. Everted and inflated internal sac: PBL almost entire, with only $l v 1$ indistinctly separated from $l v 2$, which is hypertrophied and invaginated because of a vertical internal fold. PBR missing. Three apical vesicles present, $a v 1, a v 4$, and oblong and very large av3.

DIAGNOSIS. Distinctly larger and barely more robust than $P$. ngokboci sp.n., with frontal sulci deep. Aedeagus is slightly different as well.

NAME. Refers to the Kon Chu Rang Nature Reserve, type locality of the species.

DISTRIBUTION. The type locality only.

HABITATS AND HABITS. Taken near a forest trail.

\section{The dalatensis species group}

DESCRIPTION. Body small, BL 9.5-12.7 mm. Head mostly medium-sized. Elytral interval 8 as wide as or barely narrower than 7th. Pronotum circular to subovate, with explanate lateral margin slightly concave in at least apical third; lateral bead mostly distinct in apical half; lateral groove deep yet narrow. Reflexed lateral margin of elytron and often also of pronotum with microsculpture isodiametric, coarse, contrastingly coarser than on respective discs. Pronotal basal foveae often punctate. Legs: $t i 3$ externally glabrous; $t a 2$ and $t a 3$ with conspicuous outer carinae. Right paramere long to very short.

The group includes six species.

COMMENTS. The species are arranged into three subgroups.

The nominal subgroup includes $P$. dalatensis sp.n. and $P$. honbaensis sp.n., and is defined by obliterate frontal sulci (probable synapomorphy) and elytral interval 10. Both also share the pronotum with a fairly coarse microsculpture of the lateral margin and impunctate basal foveae. Geographical distribution is southernmost in the group.

The ngoclinhensis-subgroup includes four species, P. ngoclinhensis sp.n., P. konplongensis sp.n., P. chupanphan sp.n. and $P$. kontumensis sp.n., widespread in the Tay Nguen Plateau north, and including northern part, of the Dalat Plateau. The former three species share deep frontal sulci and punctate basal foveae, as well as predominantly quadrisetose submentum. The interval 10 is well-developed in $P$. chupanphan sp.n., but absent from both $P$. ngoclinhensis sp.n. and $P$. konplongensis sp.n., being nearly indistinct, rudimentary, in this latter species.

$P$. kontumensis sp.n. is peculiar due to a number of derived characters, such as violaceous luster of the elytra, large head, subovate pronotum, with explanate lateral margin reduced to a fine lateral bead, and odd elytral intervals distinctly wider than even ones. Otherwise it matches well the distinctive character combination of the subgroup, as well as of the group, therefore it does not need erection of separate subgroup for itself.

Probable relationships of the species are as follows: $P$. kontumensis sp.n. $+((P$. ngoclinhensis sp.n. $+P$. konplongensis sp.n. $)+(P$. chupanphan sp.n. $+(P$. dalatensis sp.n. $+P$. honbaensis sp.n.)).

\section{Pterostichus dalatensis Fedorenko, sp.n.} Figs 29, 46, 48, 75-80, 114-116.

MATERIAL. Holotype $0^{7}$ (ZMMU) labelled: 'S[outh] Vietnam, Lam Dong Prov[ince]., Bi Doup — Nui Ba [Nature] Res[erve], $12^{\circ} 10^{\prime} 44^{\prime \prime} \mathrm{N} 108^{\circ} 40^{\prime} 44^{\prime \prime} \mathrm{E}$, env. Long Lanh, $\mathrm{h}=1400-1600 \mathrm{~m}, 20$ 21.IV.2008, leg. D. Fedorenko'. Paratypes (ZISP, SIEE): $50^{7} 0^{7}$, 7 오 same data, as well as additional dates 2-22.IV.2008 and 27.IV9.V.2009; $40^{\top} 0^{\top}, 3$ 우 same data except $12^{\circ} 07^{\prime} \mathrm{N} 108^{\circ} 39^{\prime} 20^{\prime \prime} \mathrm{E}, \mathrm{Bi}$

Doup Mt., N[orthern] slope, $\mathrm{h}=1700-1900 \mathrm{~m}, 4-22$. IV.2008 and 3.V.2009; $30^{7} O^{7}$, 4우, same data, except for $12^{\circ} 11^{\prime} \mathrm{N} 108^{\circ} 42^{\prime} \mathrm{E}$,

$\sim 4 \mathrm{~km}$ SSE of Hon Giao Mt., h=1500-1800 m, 2-3. and 23.IV.2008; $0^{7}$, Dak Lak Province, Chu Yang Sin Natn. Park, 12 $24^{\prime} 33^{\prime \prime} \mathrm{N}$ 108 $23^{\circ}$ '54"E, Chu Yang Sin Mt, h=1700-2000 m, 15-30.V.2014, leg. N.Poyarkov.

DESCRIPTION. Body (Fig. 29), BL 9.3-10.8 mm. Shiny black, without iridescence. Explanate lateral margin of pronotum and often also reflexed lateral margins of elytra translucent with brown or reddish-brown. Legs with femora black to (mostly) dark reddish brown; tibiae dark reddish brown, slightly paler apicad, protibiae dirty red. Antennae dark reddish-brown, slightly paler apicad. Mouthparts dirty red; mandibles and labrum more or less infuscated; ventral scrobal ridges of mandibles, apex and sides of labrum reddish. 

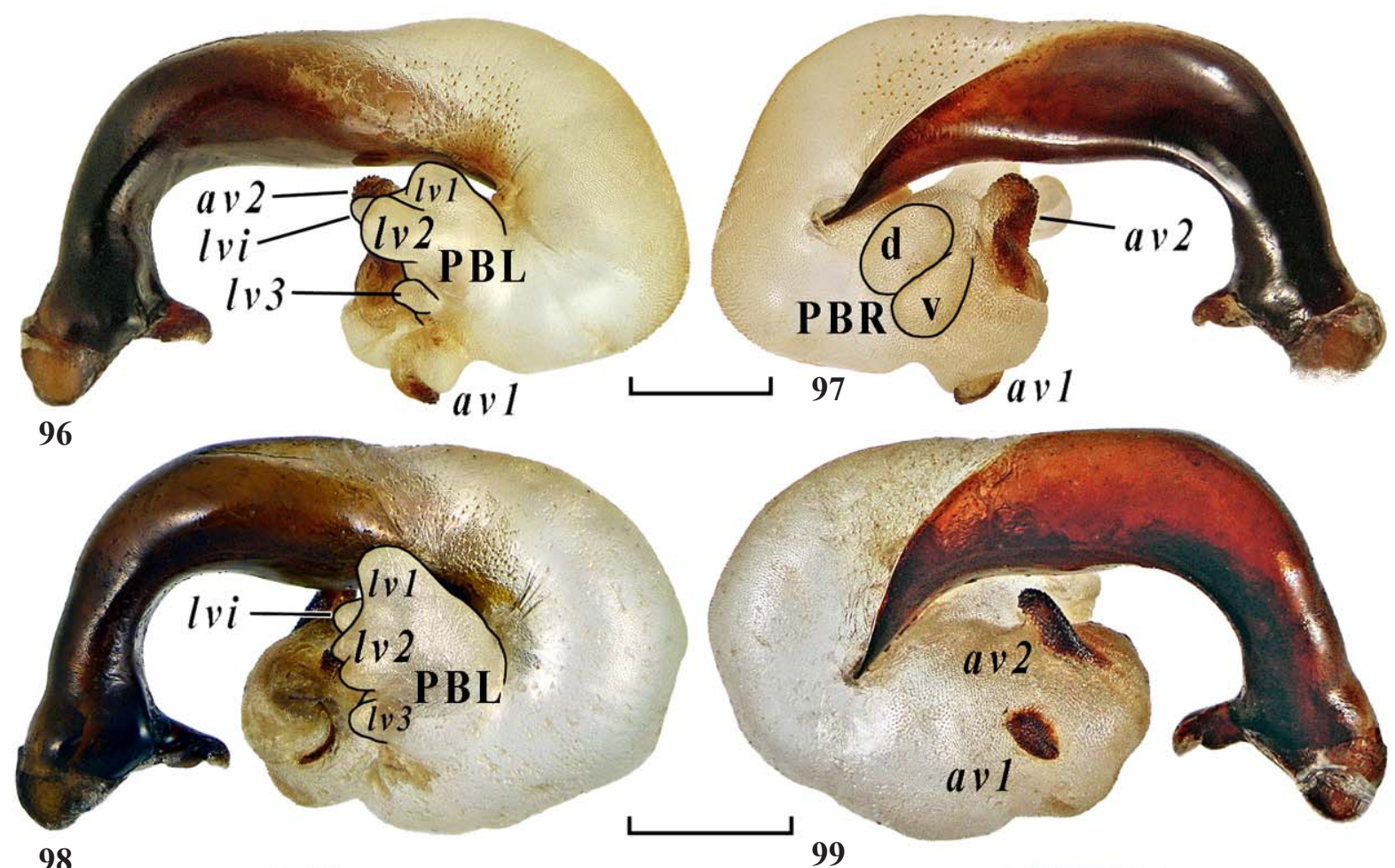

98

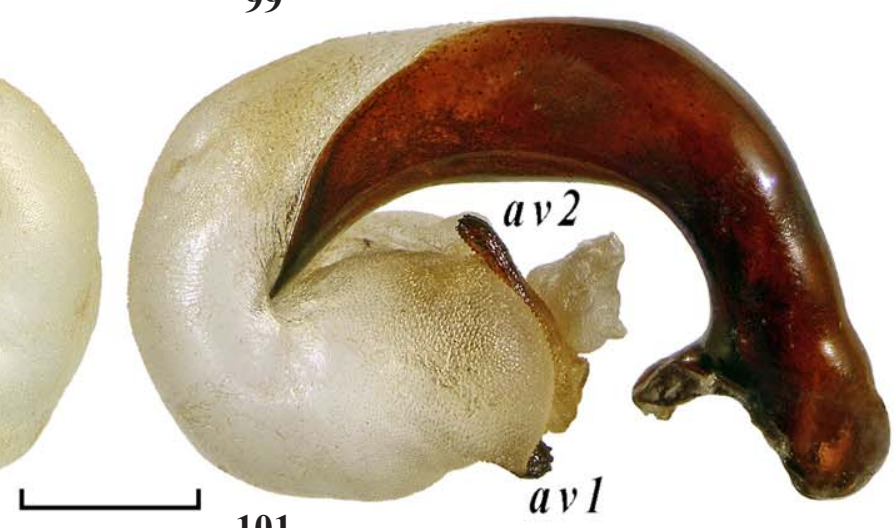

100

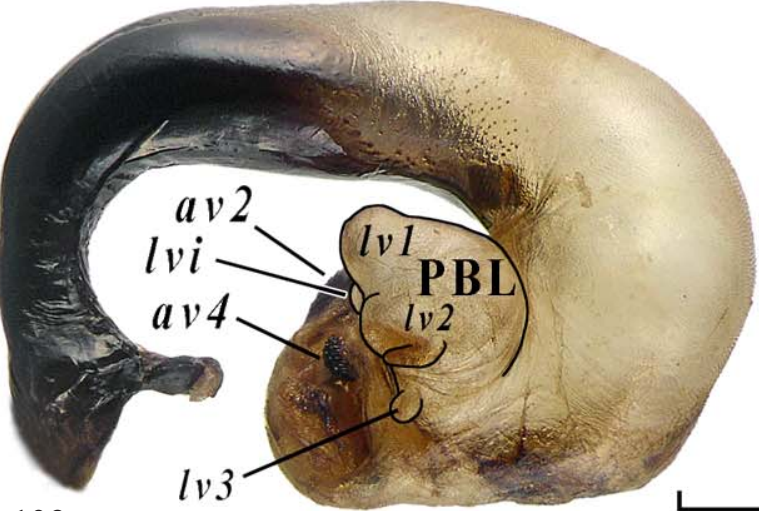

101

102

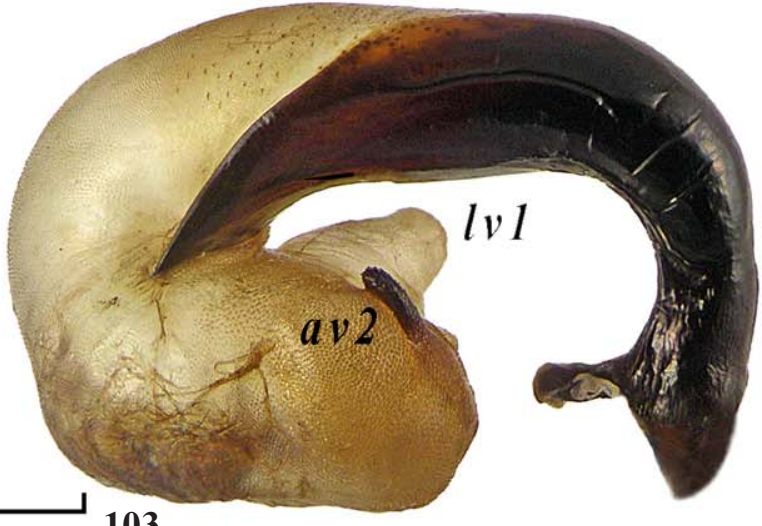

Figs 96-103. Everted and inflated internal sac of aedeagus: 96-97 — Pterostichus semiopacus sp.n.; 98-99 — P. ngokboci sp.n.; 100101 - P. konchurang sp.n.; 102-103 - P. sulcicollis sp.n.; 96, 98, 100, 102 - left aspect; 97, 99, 101, 103 — right aspect. Scale bars: $1 \mathrm{~mm}$. Abbreviations as in Figs 12-13.

Рис. 96-103. Вывернутый и надутый внутренний мешок эдеагуса: 96-97 - Pterostichus semiopacus sp.n.; 98-99 — P. ngokboci sp.n.; 100-101 - P. konchurang sp.n.; 102-103 — P. sulcicollis sp.n.; 96, 98, 100, 102 — слева; 97, 99, 101, 103 — справа. Масштаб: 1 мм. Обозначения как на рис. 12-13. 
Microsculpture superficial yet distinct on head, isodiametric and coarse on explanate lateral margin of pronotum in apical three fifths, moderately transverse on elytra.

Eyes convex, gena less than a third (ca. $0.2-0.3$ times) as long as eye. Frontal sulci obliterate. Neck constriction missing. Submentum bisetose.

Pronotum circular, PW/PL 1.19-1.30 (mean 1.24, n=4), PW/HW 1.45-1.58 (1.54), strongly and very evenly rounded on sides, with basal angles widely or very widely rounded. Base truncate. Apex evenly sinuate; apical angles narrowly to moderately rounded. Explanate lateral margin much broader basally than apically, slightly concave dorsally; lateral bead almost entire, disappearing or obsolete just in front of posterolateral seta. Lateral groove extended into outer basal sulcus at no or almost indistinct angle; outer basal sulcus slightly Cshaped, obliterate before base. Inner basal sulcus obsolete; basal fovea smooth. Median line fine, reaching base, not quite reaching apex. Both transverse impressions, basal and apical, missing.

Elytra elliptic, EW/EL 1.36-1.47 (1.42), EW/PW 1.10 1.19 (1.15), with sides rounded behind humeri, thence nearly straight and slightly diverging to the middle; preapical sinuation rather shallow; internal plica vestigial. Humeral angle obtuse. Striae deep and impunctate. Intervals convex, more so before apex, 7th, 5th and 3rd mostly confluent apicad in succession, more rarely 7 th and 3rd confluent apically; 8th barely narrower than 7th. Interval 10 short, in front of preapical sinuation. Parascutellar striole long, sometimes slightly shortened, rarely very short or posteriorly joining stria 1 . Discal seta $\mathrm{d} 2$ at or just before middle: D2/EL $0.45-0.59$ $(0.52, \mathrm{n}=5 \times 2)$. USS: $16-18$.

Underside. Prosternal process rounded in all views; apical declivity flat or subconvex, distinctly broader dorsally than ventrally, without lateral bead. Abdominal sternites II and III not laterally beaded. Mesepisternum coarsely and densely punctate; metepisternum and sides of metaventrite mostly with sparse to moderately dense medium-sized punctures; abdomen impunctate.

Aedeagus (Figs 46, 48, 75-80, 114-116): median lobe in dorsal view subequally wide, with apex long, parallel-sided and concave dorsally. Terminal lamella in dorsal view rhomboidal and somewhat subtriangular, widely rounded at left margin, with apex narrowly rounded and strongly upturned. Right paramere long, arcuate to slightly obtusely angulate, subequally wide throughout (mostly subclavate) in lateral view, subcylindric before apex in cross-section, with a pointed tip; barely concave on inner side before apex (in dorsal view). Everted and inflated inner sac: PBL entire and tapered; PBR large yet slightly convex; three apical vesicles present, $a v 2$, large $a v 3$, and $a v 4 ; a v 1$ replaced with (or modified into) a spiny patch.

DIAGNOSIS. Small-sized species; submentum bisetose and flat ( $v s$. transversely costate or subcarinate in the consubgeners); frontal sulci obliterate; pronotum circular, impunctate at base, with almost entire lateral bead, explanate margin concave dorsally just inside and covered with fairly coarse isodiametric microsculpture.

NAME. Refers to the Dalat Plateau, type locality of this species.

DISTRIBUTION. Widespread in the Dalat Plateau within Lam Dong and Dak Lak provinces.

HABITATS AND HABITS. Most specimens taken in various habitats at higher altitudes (1600-1900 m) and/or wet places at lower altitudes $(1400-1500 \mathrm{~m})$, and may be common at forest bogs. May co-occur with P. bidoupensis sp.n.

\section{Pterostichus honbaensis Fedorenko, sp.n.}

Figs 9, 30, 45, 47, 81-82.

MATERIAL. Holotype $\sigma^{7}$ (ZMMU) and paratype $q$ (SIEE), labelled: 'Vietnam, Khanh Hoa Province, Hon Ba Mt, 1400 m, IV.2003, leg. A.V.Borisenko'

DESCRIPTION. No other differences from $P$. dalatensis sp.n. than as follows: Body (Fig. 30), BL 10-10.7 mm. Shiny black, without iridescence. Microsculpture very superficial on head, as well as on explanate lateral margin of pronotum, with coarse isodiametric meshes confined to and just outside lateral pronotal groove. PW/PL 1.25-1.27, PW/HW 1.551.57. Explanate lateral margin flat; lateral bead missing. Median line fine, distinctly deeper in basal fourth. EW/EL 1.43-1.45, EW/PW 1.15-1.19. Intervals 7, 5 and 3 successively confluent apicad. Parascutellar striole missing. D2/EL 0.47-0.49 (0.48, $\mathrm{n}=2 \times 2)$. USS: $15-16$.

Prosternal process truncate apically, slightly obtuse in lateral view; apical declivity indistinctly concave, with a vestigial lateral bead. Abdomen entirely beaded on sides.

Aedeagus (Figs 45, 47, 81-82) similar, except for a shorter an less oblique apical lamella of medin lobe. Right paramere in left view arcuate, tapering apicad and pointed at tip; slender and nearly straight in dorsal view.

DIAGNOSIS. See description of the species.

NAME. Refers to the Mt. Hon Ba, type locality of the species.

DISTRIBUTION. Apparently endemic to Mt. Hon Ba, Khanh Hoa Province.

\section{HABITATS AND HABITS. No data.}

\section{Pterostichus ngoclinhensis Fedorenko, sp.n.} Figs 8, 31, 36, 55, 86, 108-109.

MATERIAL. Holotype $0^{\top}$ (ZMMU) and paratypes, $90^{7} 0^{7}$, 3 우 (SIEE) labelled: 'Vietnam, Kon Tum Prov[ince], 2-3 km W of Ngoc Linh Mt., $15^{\circ} 05^{\prime} \mathrm{N}, 107^{\circ} 57^{\prime} \mathrm{E}, \mathrm{h}=1600-2150 \mathrm{~m}$, pitfall traps, 19.III9.IV.2006, leg. A. Anichkin'. Paratypes $20^{7} 0^{7}$ (ZISP), same data, except for ' ...Central Highlands, 2-3 km W of Ngoc Linh Mt., ..., 1700-1900 m, 5.III-14.IV.2004, A.V. Abramov'.

DESCRIPTION. Body (Fig. 31), BL 10.6-11.8 mm. Slightly darker than $P$. dalatensis sp.n.: entire dorsum, including mandibles and labrum, black, without iridescence; tibiae barely paler apicad. Microsculpture hardly traceable on head, very transverse on elytra, except for reflexed lateral margin; explanate lateral margin of pronotum in apical two thirds with coarse isodiametric microsculpture.

Eyes convex, gena slightly less than a third as long as eye. Frontal sulci very deep, strongly divergent and straight or slightly S-shaped, running parallel or curved slightly inwards at the extreme posterior ends. Neck constriction hardly traceable, indistinct medially. Submentum quadrisetose.

Pronotum circular, PW/PL 1.31-1.38 (mean 1.35, n=5), $\mathrm{PW} / \mathrm{HW}$ 1.46-1.54 (1.51), strongly and very evenly rounded on sides, with widely or very widely rounded basal angles. Basal margin gently concave at middle. Apex evenly and deeply sinuate; apical angles narrowly to moderately rounded. Explanate lateral margin fairly narrow apically, a little broader behind, distinctly broader outside outer basal sulcus; lateral bead conspicuous in apical two thirds. Outer basal sulcus S-shaped to C-shaped, with base very shallow to obsolete, respectively. Inner basal sulcus deep or very so, obliterate basally; basal fovea mostly finely, moderately or sparsely, punctate, sometimes smooth. Median line fairly deep, almost reaching both base and apex, deeper in basal third or impressed in front of base. Both transverse impressions, basal and apical, usually very shallow yet traceable; the latter straight and situated a fifth from base. Posterolateral 

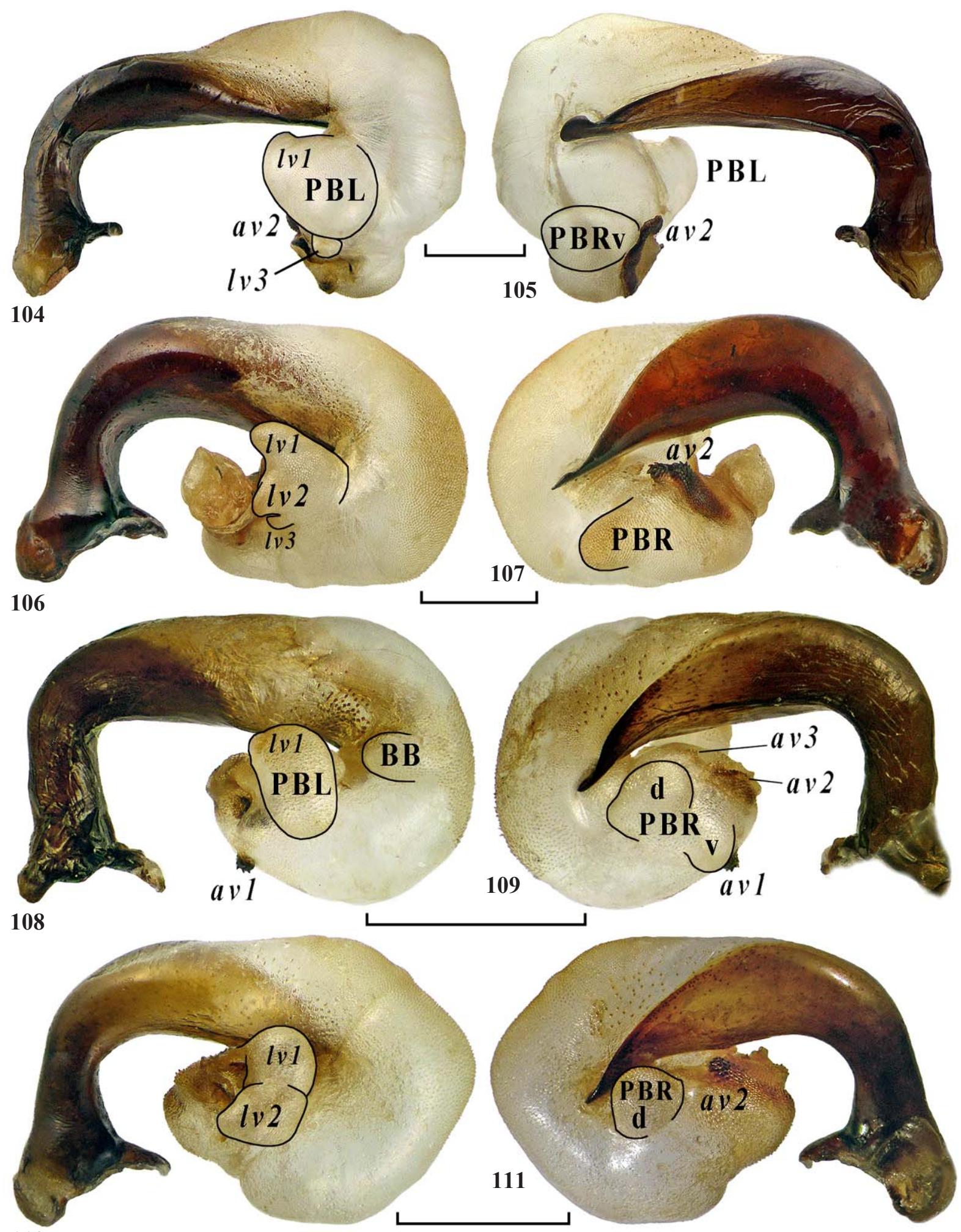

110

Figs 104-111. Everted and inflated internal sac of aedeagus: 104-105 - Pterostichus anichkini sp.n.; 106-107 - P. gialaiensis sp.n.; 108-109 - P. ngoclinhensis sp.n.; 110-111 — P. konplongensis sp.n.; 104, 106, 108, 110 — left aspect; 105, 107, 109, 111 — right aspect. Scale bars: $1 \mathrm{~mm}$. Abbreviations as in Figs 12-13.

Рис. 104-111. Вывернутый и надутый внутренний мешок эдеагуса: Everted and inflated internal sac of aedeagus: 104-105 Pterostichus anichkini sp.n.; 106-107 - P. gialaiensis sp.n.; 108-109-P. ngoclinhensis sp.n.; 110-111 - P. konplongensis sp.n.; 104, 106, 108, 110 - вид слева; 105, 107, 109, 111 - вид справа. Масштаб: 1 мм. Обозначения как на рис. 12-13. 
seta missing, occasionally (one of 14 examined specimens) both setae retained.

Elytra elliptic, EW/EL 1.45-1.49 (1.47), EW/PW 1.131.17 (1.15), nearly parallel-sided; preapical sinuation and internal plica distinct. Humeral angle right to slightly obtuse. Striae deep and impunctate. Intervals very convex, 7 th, 5 th and 3rd confluent successively apicad; 8 th as wide as 7 th. Interval 10 and parascutellar striole missing. D2/EL 0.46$0.53(0.48, \mathrm{n}=5 \times 2)$. USS: $15-17$.

Underside. Prosternal process subtruncate, subrectangular and blunt in lateral view; apical declivity slightly concave, subcarinate or finely beaded on sides. Abdomen with entire lateral bead. Mesepisternum coarsely and densely punctate, with some punctures confluent here and there; metepisternum and sides of metaventrite coarsely and rather densely punctate; sides of abdominal sternites II-IV with dense medium-sized punctures.

Aedeagus (Figs 36, 55, 86, 108-109) similar to that of $P$. sulcicollis yet small, as is apical lamella. Right paramere moderately long, arcuate, with apical part markedly narrower than basal one and apex thin in dorsal view. Everted and inflated internal sac: PBL fairly large, vertical (lv2). PBRd and PBRv subequally large, convex, slightly separated. Three apical vesicles present, small yet very distinct $a v 1$, fairly large yet poorly sclerotized $a v 2$, and almost indistinct av3.

DIAGNOSIS. Small-sized species with the pronotum lacking posterolateral seta. Additional features are as follows: submentum quadrisetose; frontal sulci very deep and fairly long; pronotum circular, with deep inner basal sulci; interval 10 absent from the elytra.

NAME. Refers to the Ngoc Linh Mts, type locality of the species.

DISTRIBUTION. Known from the type locality only. HABITATS AND HABITS. No data.

\section{Pterostichus konplongensis Fedorenko, sp.n.} Figs 32, 38, 57, 87, 110-111.

MATERIAL. Holotype $\sigma^{7}$ (ZMMU) and two paratypes $20^{7} 0^{7}$ (SIEE) labelled: 'Vietnam, Kon Tum Prov[ince]., Kon Plong Distr[ict]., 14\%44'20"N 108 $192 \mathrm{E}$, env. ngok Boc I Mt., $\mathrm{h}=1100-$ 1200 m, 8-23.IV.2015, D. Fedorenko leg.'. Paratypes (SIEE): 우, same data except $14^{\circ} 43^{\prime} \mathrm{N} 108^{\circ} 19^{\prime} \mathrm{E}, \mathrm{h}=1030 \mathrm{~m}$; $\sigma^{\prime}$, same data, except for $14^{\circ} 45^{\prime} \mathrm{N} 108^{\circ} 18^{\prime} 10^{\prime \prime} \mathrm{E}, \mathrm{h}=1200-1300 \mathrm{~m}$; 2 우, same data except $14^{\circ} 45^{\prime} \mathrm{N} 108^{\circ} 17^{\prime} 51 " \mathrm{E}, \mathrm{h}=1300-1400 \mathrm{~m}, 8-10$.VI.2016; $20^{7} 0^{7}$, 'Vietnam, Kon Tum Prov[ince], 2-3 km W of Ngoc Linh Mt., $15^{\circ} 05^{\prime} \mathrm{N}, 107^{\circ} 57^{\prime} \mathrm{E}, \mathrm{h}=1600-2150 \mathrm{~m}$, pitfall traps, 19.III9.IV.2006, leg. A. Anichkin'; $O^{7}$ ' 'Vietnam, Gia Lai Province, 40 $\mathrm{km}$ ENE of Pleiku, $14^{\circ} 13^{\prime} 21^{\prime \prime N} / 108^{\circ} 19^{\prime} 55^{\prime \prime} \mathrm{E}$, Kon Ka Kinh Nat[io]n[al]. Park, h=1490 m, 21-30.V.2017, D. Fedorenko leg.'.

DESCRIPTION. As compared with $P$. ngoclinhensis sp.n.: Body (Fig. 32), BL 10.4-12.7 mm. Explanate lateral margin of pronotum behind the middle mostly with slight purplish iridescence; elytra similarly iridescent and very slightly sericeous behind the middle. Explanate lateral margin of pronotum with very superficial microsculpture, isodiametric in apical half while longitudinal behind the middle.

Frontal sulci mostly nearly straight. Submentum quadrisetose (bisetose in one specimen), lateral setae vestigial.

Pronotum bisetose on each side, larger and thence wider relative to both head and elytra, PW/PL 1.29-1.35 (mean 1.33, n=5), PW/HW 1.55-1.66 (1.63). Apex slightly less deeply sinuate in general; apical angles a bit more widely rounded and more projecting. Explanate lateral margin flat and very wide in basal two thirds; lateral bead obliterate behind the middle. Outer basal sulcus C-shaped. Inner basal sulcus obliterate; basal fovea finely and rather densely punctate.

Elytra elliptic, EW/EL 1.44-1.53 (1.50), EW/PW 1.071.16 (1.10), rounded on sides. Humeral angle slightly obtuse. Intervals convex, 7 th, 5th, 3rd and 2nd confluent apicad in succession. D2/EL 0.43-0.53 (0.48, $\mathrm{n}=5 \times 2)$. USS: 16 .

Underside. Prosternal process slightly less blunt apically; apical declivity subconvex to slightly concave, mostly faintly beaded on sides. Mesepisternum, metepisternum and sides of metaventrite slightly less densely punctate; sides of abdominal sternites II-IV rather sparsely and shallowly punctate, except for a group of fairly dense medium-sized punctures just behind basal margins of sternite II and often also III.

Aedeagus (Figs 38, 57, 87, 110-111) similar, except for a larger apex of median lobe. Everted and inflated internal sac: PBL bipartite, divided apically into two subequal parts, $l v 1$ and $l v 2$. PBR (PBRd) fairly large, projecting laterad and slightly dorsad. Two apical vesicles present, $a v 4$ and $a v 2$, the latter extended ventrad into a poorly sclerotized stripe covered with spicules that are slightly larger than surrounding ones.

NAME. Refers to the Kon Plong District, Kon Tum Province, where most of the type series was collected.

DIAGNOSIS. Similar to P. ngoclinhensis sp.n., being distinguished chiefly by the pronotum bisetose on each side, with lateral margin widely explanate and inner basal sulcus obliterate, and elytral interval 10 being short and preapical.

DISTRIBUTION. Kon Tum and Gia Lai provinces.

HABITATS AND HABITS. As for the subgenus. In the Ngoc Boc Mts, P. konplongensis sp.n. co-occurs with $P$. ngokboci sp.n., but in a wider altitude range, 1100-1400 m, whereas P. ngokboci sp.n. has not been found below $1200 \mathrm{~m}$.

\section{Pterostichus chupanphan Fedorenko, sp.n.} Figs 33, 41, 56, 83-84.

MATERIAL. Holotype $0^{7}$ (ZMMU) labelled: 'Vietnam, Dak Lak Prov.[ince], Chu Yang Sin Natn. Park, $12^{\circ} 22^{\prime} 40$ "N $108^{\circ} 21^{\prime} 11^{\prime} E, 1.5 \mathrm{~km} \mathrm{~W}$ [of ] Chu Pan Phan Mt, h=1650 m, 30.III11.IV.2012, D. Fedorenko leg.'. Paratype + (SIEE), same data

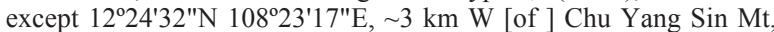
$\mathrm{h}=1500-1600 \mathrm{~m}, 15-30 . \mathrm{V} .2014$.

DESCRIPTION. As for $P$. ngoclinhensis sp.n. except as follows: Body (Fig. 33), BL 10.2-11.2 mm. Explanate lateral margin of pronotum with superficial longitudinal microsculpture. Frontal sulci shorter, not quite reaching anterior supraocular seta. Neck constriction indistinct. Submentum bisetose (in male specimen) or quadrisetose (in female specimen).

Pronotum bisetose on each side: PW/PL 1.25-1.27, PW/ HW 1.50-1.56. Apex nearly truncate, except for projecting apical angles. Explanate lateral margin slightly broader in general. Lateral bead very fine, nearly obsolete, obliterate in basal third and at apical angles. Inner basal sulcus very shallow to obsolete; basal fovea coarsely and densely punctate.

Elytra longer, EW/EL 1.53-1.56, EW/PW 1.13-1.17. Humeral angle obtuse. Striae deep and impunctate. Intervals convex, more so laterally and before apex; 7 th, 5 th and $3 \mathrm{rd}$ confluent successively apicad (paratype) or 7 th and 3 confluent apically (holotype); 7 th distinctly wider than 8 th. Interval 10 preapical and short. Discal seta $\mathrm{d} 2$ inserted two fifths from apex, D2/EL 0.39-0.44 (0.42, n=2×2). USS: $16-17$.

Underside. Prosternal process subtruncate, with a faint apical bead, rather sharply rectangular in lateral view; apical declivity barely convex, with no lateral bead. Mesepisternum coarsely, 
moderately to densely punctate; metepisternum and sides of metaventrite slightly less densely punctate; sides of abdominal sternites III and IV very finely punctate; propleura finely and sparsely punctate just outside sternopleural suture.

Aedeagus (Figs 41, 56, 83-84): median lobe very similar to that of $P$. semiopacus sp.n. Right paramere long, with apical half being very slender, tapered, and bent at right angle.

DIAGNOSIS. See description of the species.

NAME. Refers to the Mt. Chu Pan Phan, type locality of this species.

DISTRIBUTION. The type locality only.

HABITATS AND HABITS. This species co-oocurs with P. abramovi sp.n.
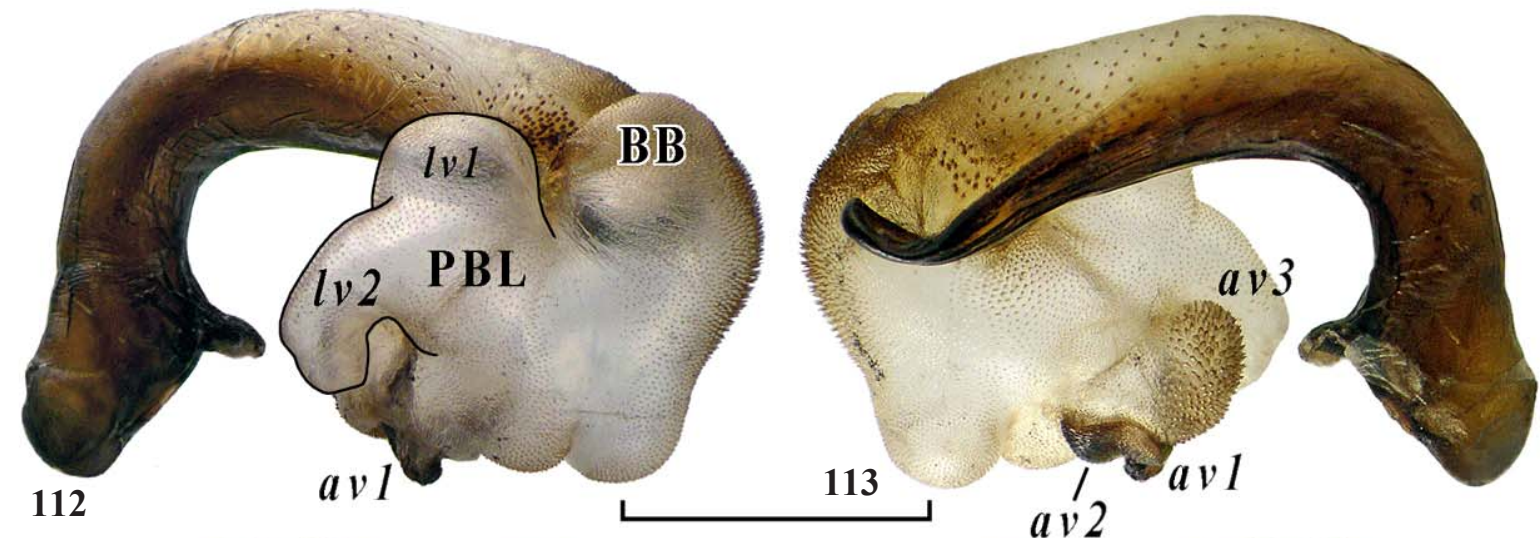

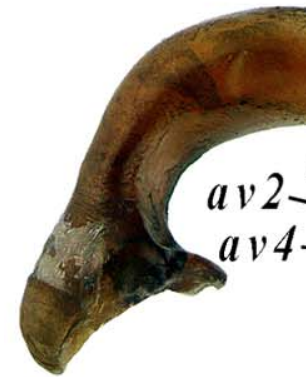

114

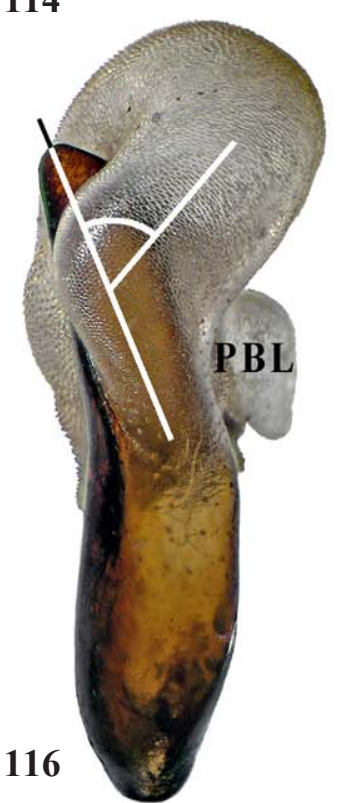

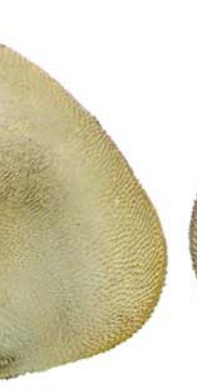

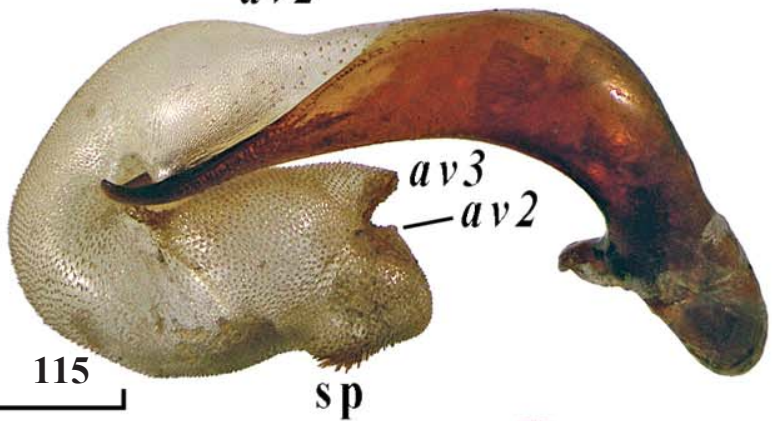

sp
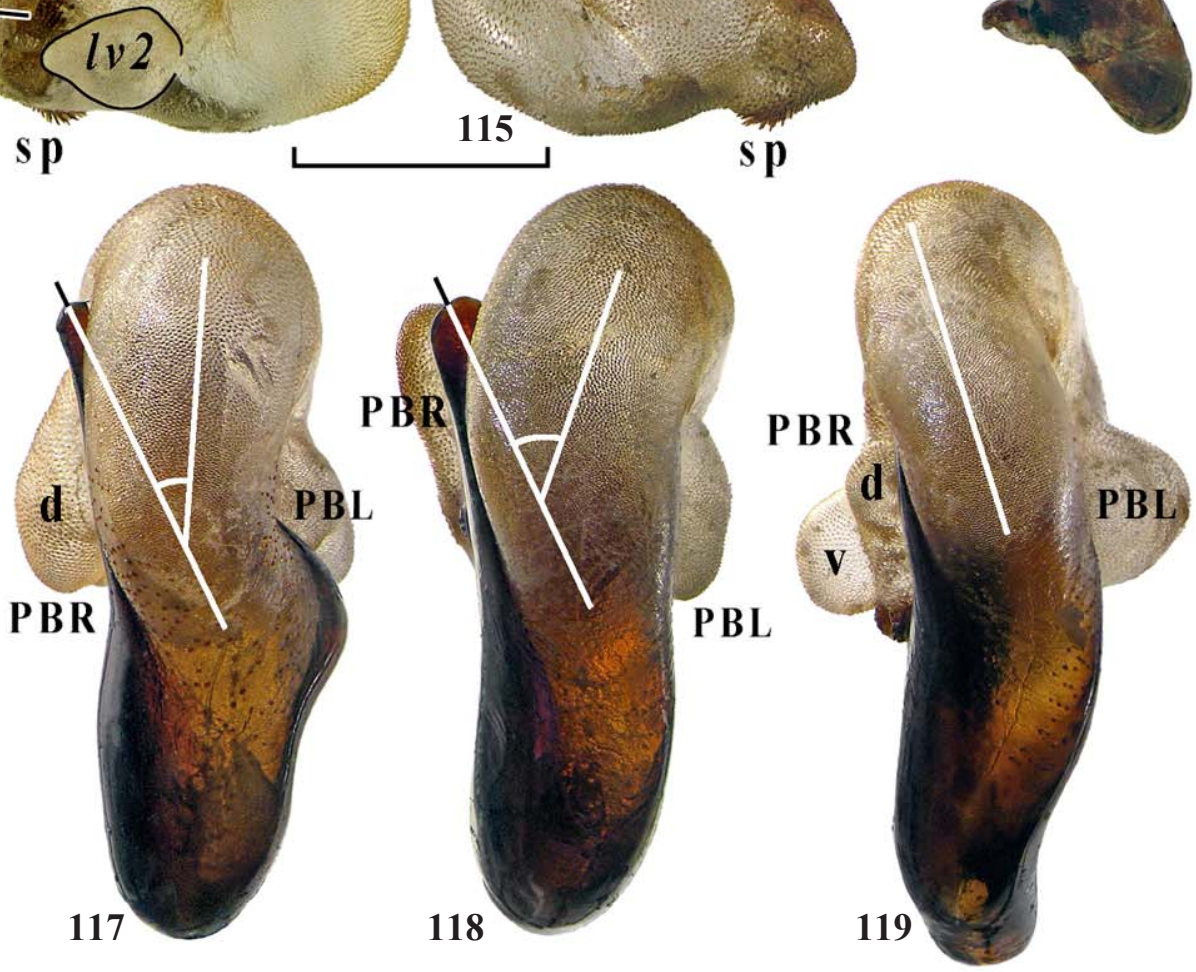

Figs 112-119. Everted and inflated internal sac of aedeagus: 112-113 - Pterostichus kontumensis sp.n.; 114-116 — P. dalatensis sp.n.; 117 - P. abramovi sp.n.; 118 - P. gialaiensis sp.n.; $119-$ P. annamita chuyangsin ssp.n.; 112, 114 - left aspect; 116-119 - dorsal aspect. Scale bars: $1 \mathrm{~mm}$. Abbreviations as in Figs 12-13.

Рис. 112-119. Вывернутый и надутый внутренний мешок эдеагуса: 112-113 — Pterostichus kontumensis sp.n.; 114-116 — P. dalatensis sp.n.; 117 - P. abramovi sp.n.; 118 - P. gialaiensis sp.n.; 119 - P. annamita chuyangsin ssp.n.; 112, 114 — слева; 116119 - дорзально. Масштаб: 1 мм. Обозначения как на рис. 12-13. 


\section{Pterostichus kontumensis Fedorenko, sp.n.} Figs 10, 28, 43, 58, 85, 112-113.

MATERIAL. Holotype $\sigma^{\top}$ (ZMMU) and paratypes $3 \sigma^{7} \sigma^{\top}$ (SIEE) labelled: 'Vietnam, Kon Tum Prov[ince], 2-3 km W of Ngoc Linh Mt., $15^{\circ} 05^{\prime} \mathrm{N}, 107^{\circ} 57^{\prime} \mathrm{E}, \mathrm{h}=1600-2150 \mathrm{~m}$, pitfall traps, 19.III9.IV.2006, leg. A. Anichkin'. Paratype $\sigma^{T}$ (ZISP), same data except '..., Central Highlands, 2-3 km W of Ngoc Linh Mt., ..., 5.III14.IV.2004, A.V. Abramov'

DESCRIPTION. Body (Fig. 28), BL 9.5-10.2 mm. Shiny black, elytra with faint violaceous luster. Legs dark brown, with slightly paler tarsi. Antennae rather dark reddish-brown, with segments 5-11 increasingly paler apicad from reddishbrown to red, except for darker median strip on anterior and posterior sides. Palps dirty red, labrum slightly reddish apically and laterally. Microsculpture superficial on head, superficial and moderately to strongly transverse on elytra. Lateral groove of pronotum and reflexed lateral margin of elytron with coarse isodiametric microsculpture.

Head large; eyes fairly small, slightly flattened and smoothly extended into genae; these latter three quarters as long as eyes. Frontal sulci rather shallow, shallower posteriorly, running parallel or slightly diverging behind clypeus, then strongly curved towards and almost reaching the level of anterior supra-ocular seta. Neck constriction indistinct. Submentum bisetose.

Pronotum bisetose on each side, subovate, much narrower basally than apically, PW/PL 1.31-1.34 (1.32, n=4), PW/ HW 1.26-1.28 (1.27); sides strongly rounded in apical half, less so behind. Base truncate, basal angles obtuse and rather narrowly rounded. Apex deeply and evenly sinuate; apical angles narrowly rounded. Explanate lateral margin in form of a fairly narrow lateral bead extended along sides of base to inner basal sulcus, disappearing at or just inside it. Outer basal sulcus merged into lateral groove; inner basal sulci parallel and very deep; basal fovea smooth. Median line moderately deep, (almost) reaching base, obliterate before apex. Basal and apical transverse impressions hardly traceable to missing.

Elytra elliptic, EW/EL 1.41-1.47 (1.44), EW/PW 1.171.20 (1.18), with sides almost straight and very slightly diverging in basal half; preapical sinuation and internal plica distinct. Humeral angle obtuse. Striae deep and impunctate. Intervals convex, more so before apex, 3rd, 5th and 7 th distinctly wider than adjacent ones; intervals 3 and 7 confluent apically; 8th narrow and costate in apical third. Interval 10 broken in apical half into 1-3 short and widely separate sections. Parascutellar striole short. D2/EL 0.38-0.46 (0.43, $\mathrm{n}=4 \times 2$ ). USS: 15 , sometimes 16 .

Underside. Prosternal process subtruncate; nearly rectangular, with rounded apex, in lateral view; apical declivity flat to indistinctly concave, sharply edged to vaguely beaded on sides. Apical 2-2.5 sternites finely beaded on sides. Mesepisternum, metepisternum and sides of metaventrite moderately coarsely, sparsely to densely punctate; abdominal sternites III-V finely and more or less densely punctate on sides.

Aedeagus (Figs 43, 58, 85): apical lamella upturned, concave dorsally; in dorsal view long and rectangular, with latero-apical angles widely rounded; apex of the lamella slightly thickened in lateral view. Right paramere very short. Everted and inflated internal sac and its some constituent parts very large (Figs 112-113): PBL large bipartite, with $l v 1$ and $l v 2$ curved ventrad. PBR missing; a large ventral bulb present below apical lamella. Three apical vesicles present, $a v 1, a v 2$ as a flat and strongly sclerotized fold, and $a v 4$, modified into a large spiculate bulb.
DIAGNOSIS. A small-sized species with slightly violaceous elytra, large head, long genae, moderately deep frontal sulci; pronotum without explanate lateral margin, but with a fine lateral bead and inner basal sulci deep and reaching base. Elytral intervals 3, 5 and 7 much wider than the adjacent ones; interval 10 broken.

NAME. Refers to the provenance of the species, Kon Tum Province.

DISTRIBUTION. The type locality only.

HABITATS AND HABITS. This species is sympatric and may co-occur with other species of the subgenus recorded in the Ngoc Linh Mts.

\section{The gialaiensis species group}

DESCRIPTION. Body large, BL 17 mm. Elytral interval 8 barely narrower than 7 th in basal half, distinctly narrower in apical third. Pronotum subcircular; with a fairly convex explanate lateral margin devoid of lateral bead; lateral groove narrow. Dorsal microsculpture very superficial. Right paramere moderately long, with slightly desclerotized apex.

COMMENTS. This group includes a single species, $P$. gialaiensis sp.n. It shares subequally wide elytral intervals 7 and 8 with the members of the dalatensis-group, being most similar to $P$. ngoclinhensis sp.n. in having moderately long right paramere and no interval 10 . In endophallic structure, $P$. gialaiensis sp.n. resembles also $P$. konplongensis sp.n. In both species, PBR is distinctly projecting, av3 and av4 only present, and PBL is similar, except for being bipartite in the latter $v s$. tripartite in the former.

On the other hand, much larger body size, distinctly punctate elytral striae and superficial microsculpture of pronotal and elytral lateral margins suggest that $P$. gialaiensis sp.n. is not a member of the dalatensis-group. Some of these characters, i.e., the larger body, the microsculpture, and a tripartite endophallic PBL ( $v s$. entire or bipartite in the dalatensis-group), are characteristic of the annamita species group. Two members of the annamita-group, $P$. ngokboci sp.n. and $P$. konchurang sp.n., are most similar to $P$. gialaiensis sp.n. in appearance and distribution. Besides, $l v 2$ is invaginate in the fromer two (as well as in P. sulcicollis sp.n.), while $P$. gialaiensis sp.n. exhibits a similar condition.

\section{Pterostichus gialaiensis Fedorenko, sp.n.}

Figs 27, 74, 106-107, 118.

MATERIAL. Holotype $\sigma^{\prime}$ (ZISP) labelled: 'Vietnam, GialaiKontum [= Gia Lai — Kon Tum province], Buonloi [=Buon Loi], 15 XI 1993, Gorokhov' [hw].

DESCRIPTION. Body (Fig. 27), BL 16.9 mm. Shiny black, elytra behind the middle slightly iridescent. Antennae rather dark brown, with segments 5-11 increasingly paler along ridges. Palps dirty reddish-brown. Microsculpture hardly traceable over head, very transverse on elytra. Explanate lateral margin of pronotum with nearly indistinct microsculpture; reflexed lateral margin of elytron with highly superficial isodiametric meshes.

Eyes convex, gena a fourth as long as eye. Frontal sulci long, reaching the level of anterior supra-ocular seta, Sshaped, i.e., strongly diverging yet running parallel just anteriorly and posteriorly, very deep throughout, more so behind clypeus. Neck constriction hardly traceable medially. Submentum bisetose.

Pronotum bisetose on each side, nearly circular, PW/PL 1.29 , PW/HW 1.57, strongly and very evenly rounded on sides, with widely rounded basal angles. Basal margin gently concave at middle. Apex evenly concave between narrowly rounded apical angles. Explanate lateral margin narrow, al- 
most bead-like before anterolateral seta, slightly broader behind, wide only outside outer basal sulcus. Outer basal sulcus C-shaped, with a few fine punctures at bottom; inner basal sulcus very deep, finely punctate at bottom; basal fovea otherwise smooth. Median line moderately deep, almost reaching base, obliterate before apex. Both transverse impressions, basal and apical, missing.

Elytra elliptic, EW/EL 1.58, EW/PW 1.14, with sides poorly rounded in second and third fifths; preapical sinuation and internal plica distinct. Humeral angle obtuse. Striae deep, very densely punctate, punctures becoming gradually larger in size outwards from very fine in stria 1 to medium-sized in stria 10 . Intervals convex, very convex before apex, 7th, 5th and 3rd confluent apicad in succession; 3rd merged into apical bead; 8 th as wide as 7 th in basal half, subcostate, distinctly narrower than 7 th in apical third. Interval 10 and parascutellar striole missing. D2/EL 0.44-0.45. USS: 20-21.

Underside. Prosternal process subtruncate, sharply subrectangular in lateral view; apical declivity flat, with sharp lateral edges. Abdomen entirely beaded on sides. Punctation as in $P$. ngoclinhensis sp.n., yet finer and sparser on metasternum.

Legs: $t i 3$ externally with one (right) or no (left) seta; $t a 2$ with conspicuous outer carinae, $t a 3$ with slightly weaker ones.

Aedeagus (Figs 74, 106-107, 118): apical lamella in dorsal view large, triangular, widely rounded at tip, thin in lateral view, with vestigial dorso-apical tooth. Right paramere moderately long, sabre-shaped, slightly desclerotized at apex. Everted and inflated internal sac: PBL tripartite, with $l v 1$ and $l v 2$ fairly large, $l v 3$ small and contiguous to $l v 2$. PBR large, projecting proximad. Two apical vesicles present, large av3 (perhaps fused to av2) and minute yet well sclerotized av4.

DIAGNOSIS. The only large-sized species of the group, easily recognizable among the other large-sized consubgeners by having distinctly punctate elytral striae. Additional features are as follows: submentum bisetose; frontal sulci very deep and fairly long; inner basal sulcus of pronotum deep; interval 10 missing.

NAME. Refers to Gia Lai Province in central Vietnam, where this species was collected.

DISTRIBUTION. Known from the type locality only.

HABITATS AND HABITS. No data.

\section{Pterostichus cavicollis Straneo, 1984} Fig. 34.

Straneo, 1984: 264 ('Tonkin, Montes Mauson’ [= Mau Son Mts]). MATERIAL. Paratype, photographed 9 (MSNM) with labels: 'Tonkin, Montes Mauson, April, May, 2-3000', H.Fruhstorfer', 'Allotypus, Pterostich., cavicollis [hw]' [red], 'Pterostichus cavicollis n.sp. [hw], det. S.L. Straneo 1983, Allotypus'.

REDESCRIPTION. Unnecessary except the following characters of the paratype (Fig. 34). BL $13.3 \mathrm{~mm}$. Microsculpture superficial on head.

Head medium-sized, eyes moderately large and moderately prominent. Frontal sulci thin, moderately deep, shallower posteriorly; running parallel anteriorly, then strongly curved towards, albeit not quite reaching, anterior supraocular seta. Neck constriction indistinct. Submentum quadrisetose.

Pronotum circular, with basal and apical margins barely convex, nearly straight; basal angles rounded off, apical angles slightly projecting, PW/PL 1.24, PW/HW 1.69. Explanate lateral margin reflexed and rather wide, much wider just before base than apically; lateral bead distinct in apical two thirds. Outer basal sulcus indistinctly C-shaped, directly extended apicad into a ?shallow lateral groove; inner basal sulci very deep basally, traceable before middle, yet not quite reaching basal margin; basal fovea finely and rather sparsely punctate along basal sulci near basal margin. Median line rather fine, obliterate basally and at apically. Both transverse impressions, basal and apical, missing. Apical bead interrupted just medially.

Elytra elliptic, EW/EL 1.42, EW/PW 1.19, with humeri rounded off following very short and oblique bases. Humeral angle obtuse. Striae very deep, finely punctate at bottom. Intervals convex, very convex before apex; intervals 7 th, 5 th and 3rd confluent apicad in succession; 8th barely narrower than 7 th. Interval 10 missing. Parascutellar striole missing or short. D2/EL 0.35. USS: 7+1+9.

Underside. Mesepisternum, metepisternum, and sides of metaventrite moderately punctate; abdominal sternites II and III finely and rather sparsely punctate on sides.

Legs: at least ta3 (tm 1-2) with blunt yet distinct outer carinae.

DIAGNOSIS. A large-sized species having a circular pronotum, the elytra with finely punctate striae, subequally wide intervals 7 and 8 , no interval 10 . It is very peculiar also because of its range (northern $v s$. central Vietnam) and some characters, including nearly indistinct humeri, uncharacteristic of the subgenus.

DISTRIBUTION. Only known from the type locality, Mt. Mau Son in Lang Son Province.

HABITATS AND HABITS. No data.

COMMENTS. According to the original description, this species has smooth elytral striae, $6+2+9$ umilical setae in the elytral interval 9, and the holotype is $16.5 \mathrm{~mm}$ in length. Based on the paratype's having elytral striae distinctly, though finely, punctate, the smooth striae are not necessarily characteristic of the species. The paratype label says that $P$. cavicollis was collected at 2-3,000 ft ( $c a$. 600-900 m), not ' $2-3,000$ $\mathrm{m}$ ', as the original description indicates.

\section{Discussion}

In having a more or less circular pronotum, Vietosteropus subgen.n. is most similar to the northern Oriental and Palearctic subgenera Sinosteropus Sciaky, 1994, Eosteropus Tschitschérine, 1902, and Circinatus Sciaky, 1996. However, the metatrochanteral seta characteristic of the latter three taxa suggests that they are not closely related to Vietosteropus subgen.n. The subgenera Petrophilus Chaudoir, 1838 (including Feroperis Lafer, 1979), Wrasiellus Shi, Sciaky, 2013 and Neohaptoderus Tschitschérine, 1898 appear to be among its closer relatives, as suggested by one discal seta on the elytron and rather rounded basal angles of the pronotum shared by Vietosteropus subgen.n. and some Neohaptoderus. However, Petrophilus, Wrasiellus and Neohaptoderus have the pronota less modified than that of Vietosteropus subgen.n. In particular, both basal sulci, inner and outer, are distinct; and the lateral margin is bead-like (vs. wide and reflexed) and well separated from the outer basal sulcus, this combination being probably ancestral for Pterostichus.

The subgenus Pseudethira Sciaky, 1996 does not seem to be closely related, albeit similar to Vietosteropus subgen.n. in leg chetotaxy, deep mentum pits, outer 
basal sulcus of the pronotum completely or almost completely reduced, and the elytral interval 10 being more or less developed in many species of that subgenus. The female reproductive tract is similar to that of Vietosteropus subgen.n., except for the modified gonocoxite and glabrous gonosubcoxite.

Some external characters and features of the aedeagus (Table 1) probably evolved independently in each species group of Vietosteropus subgen.n. The number of the setae on the submentum decreased from four to two, with some specimens retaining vestigial outer setae. Obliterate frontal sulci certainly evolved independently in $P$. sulcicollis sp.n. and $P$. anichkini sp.n., on one hand, and in $P$. dalatensis sp.n. and $P$. honbaensis sp.n., on the other. The length of the right paramere changed accordingly. However, it is hard to tell which condition should be considered as ancestral in the subgenus: absent or short $v s$ long elytral interval 10, or longer vs shorter paramere. Some Pseudethira have long interval 10, which suggests this condition to be ancestral for Vietosteropus subgen.n., but derived for Pterostichus.

Bisetose $f e 3$ is a plesiomorphic character; other plesiomorphies may include externally setose $t i 3$ and probably the very long interval 10 . This character combination in $P$. semiopacus sp.n. suggests rather a basal position of that species in the subgenus. On the other hand, the wide and deep lateral pronotal groove is an apparently derived feature shared by $P$. semiopacus sp.n. with $P$. sulcicollis sp.n. and $P$. anichkini sp.n.

The mentum pits have undergone independent reduction as well. They are small yet deep to very deep in most species, but almost to completely reduced in $P$. abramovi sp.n. and $P$. semiopacus sp.n. (the annamita-group) as well as in $P$. dalatensis sp.n. and $P$. honbaensis sp.n. (the dalatensis-group).

All the Vietosteropus species can be arranged into two groups based on a particular aedeagus type defined by three interdependent characters: shape of the everted and inflated endophallus, shape of the apex of the median lobe (apical lamella) and presence/absence of right dorso-apical tooth of the apical lamella (Table 1).

In the type 1 aedeagus (Figs 116-117), the median lobe is straight or concave at right margin basal to the apical lamella. The lamella is large, quadrangular in dorsal view (Figs. 47-48, 50, 52, 54, 56, 58) and either bent dorsad or ending in a distinct dorso-apical tooth, which probably help to deflect the endophallus to the left during eversion. As a result, totally everted endophallus gets first bent to the left, then ventrobasad, leaving the apical lamella exposed in dorsal view.

In the type 2 aedeagus (Fig. 119), the median lobe is convex at right margin, with apical lamella toothless and shaped as an isosceles triangle (Figs. 51, 53, 55, 57). Since no deflector is present, the everted endophallus is bent ventrobasad only, with the apex of the median lobe lean on endophallus ventral wall and concealed in dorsal view with the endophallus.

Only two species show conditions intermediate between the two types. Pterostichus semiopacus sp.n. matches well the type 2 aedeagus, yet has a vestigial dorsolateral tooth and the apex of median lobe characteristic of the type $1 ; P$. gialaiensis sp.n. has everted endophallus similar to the type 1 (Fig. 118), but with apical lamella large, exposed, with just a minute tooth.

Thus, in Vietosteropus subgen.n., the shape of the apex of the median lobe may be function-dependent, which makes homoplasies very likely. Many unrelated species are indeed very similar in this respect. Pterostichus annamita, $P$. sulcicollis sp.n., $P$. ngoclinhensis sp.n. and $P$. konplogensis sp.n. provide good examples of the type 2 aedeagus (Figs 51, 53, 55, 57), while $P$. dalatensis sp.n. (Fig. 48) and P. abramovi sp.n. (Fig. $50)$, of the type 1 .

Right paramere provides more evidence on the relationships of the species, even though its length varies widely from species to species. Notably, all the species that have the longest paramere are confined to the Dalat Plateau, even though they represent two different lineages (species groups). The right paramere being short or long (compare Figs 60-67, 71 vs Figs 68-69, 72-74), combined with some other characters and vicariant distribution, supports the recognition of two subgroups within the annamita-group.

Except for P. kontumensis sp.n., a distinctive species with the shortest paramere in the subgenus, the other two species of the dalatensis-group from the northern Tay Nguen Plateau have moderately long parameres (Fig. 86-87). They are very similar to $P$. chupanphan sp.n. from the northernmost Dalat Plateau in appearance, including deep frontal sulci and punctate basal foveae of the pronotum. On the other hand, $P$. chupanphan sp.n. share a well-developed interval 10 and a long paramere (Figs. 75-83) with two closely allied species, $P$. dalatensis sp.n. and $P$. honbaensis sp.n., distinctive in having obliterate frontal sulci and smooth pronotal basal sulci. This suggests that $P$. chupanphan sp.n. may be a link between northern (P. konplongensis sp.n. and P. ngoclinhensis sp.n.) and southern ( $P$. dalatensis sp.n. and $P$. honbaensis sp.n.) species, and that a shorter paramere could have evolved into the longest one as a northern ancestor expanded southwards and diversified. This scenario also applies to the annamita-group.

Finally, some endophallic parts vary considerably from species to species in shape and to some extent in relative position - which means these parts may not be homologous in all species, e.g., the vesicle referred to as av3 in one species may be either novelty or homologous to av2 in others.

ACKNOWLEDGEMENTS. I am indebted to Dr. Boris Kataev (ZISP) for the loan of material under his care and Dr. Fabrizio Rigato (MSNM) for high-resolution photograps of specimens. I am also very grateful to Dr. Alexander Anichkin (Yoshkar-Ola) for donating specimens. I thank Vassili Belov (College Station, TX, USA) for suggestions that have improved the manuscript. The study was supported by the Russian Academy of Sciences Biodiversity Program. 


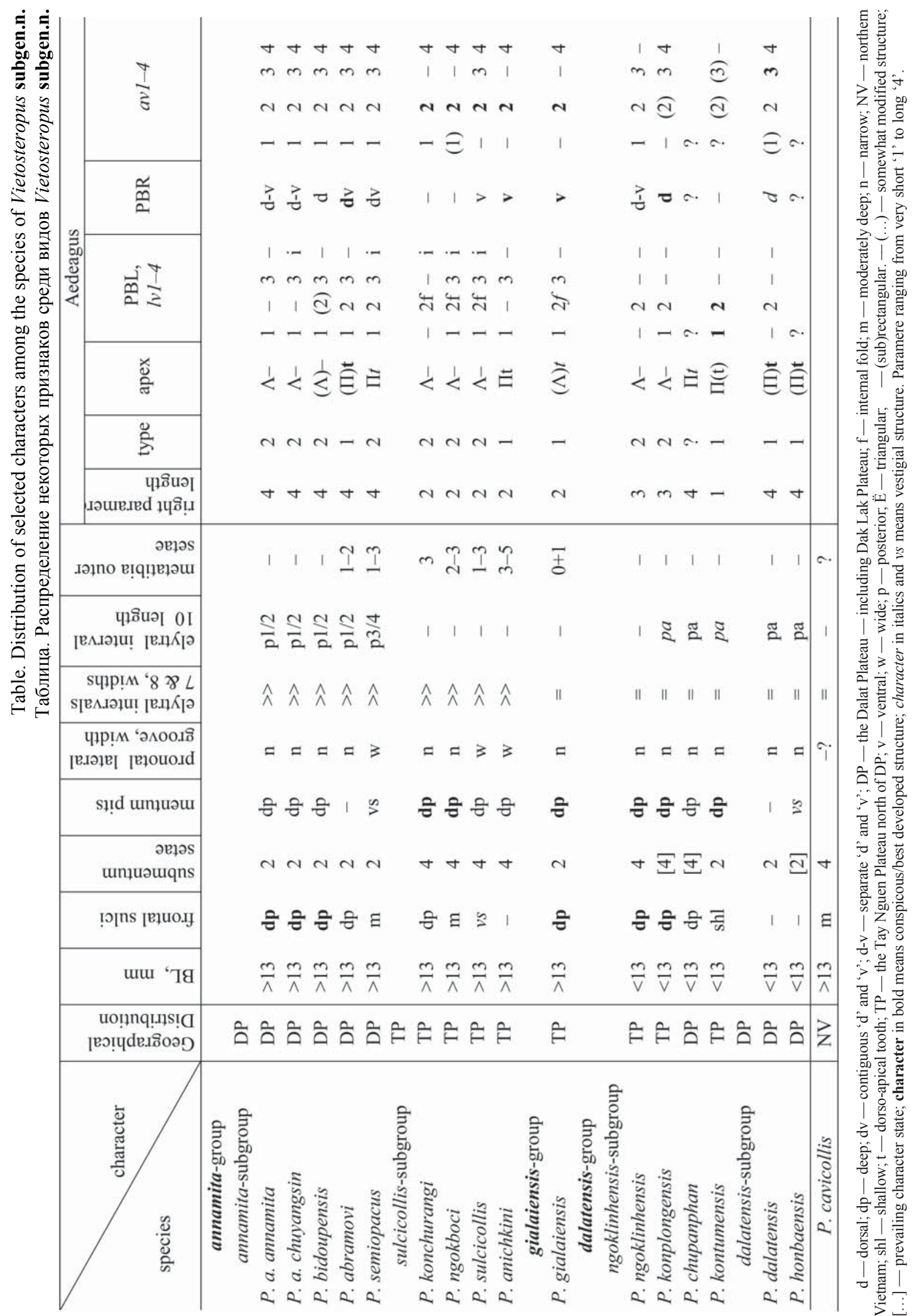




\section{References}

Allegro G., Sciaky R. 2010. Review of the Chinese subgenus Circinatus of Pterostichus, with description of six new species (Coleoptera, Carabidae) // Boll. Mus. Stor. Nat. Verona. Vol.34 Bot. \& Zool. P.3-18.

Faccini S., Sciaky R. 2000. Revision of Pterostichus Bonelli, 1810 subg. Pseudohaptoderus Tschitscherine, 1888 and description of new taxa (Coleoptera: Carabidae, Pterostichinae) // Koleopt. Rundsch. Bd.70. S.1-10.

Morvan D.m., 1992. Contribution à la connaissance des Coléoptères Carabidae de Thaïland // Elytron. 1991. Vol.5. P.55-62

Schmidt J. 2006. Die Pterostichus-Arten des subgenus Pseudethira Sciaky, 1996, in Zentral- und West Nepal (Coleoptera, Carabidae): Taxonomie, Phylogenie, Biogeographie // Hartmann M. Weipert J. (eds.). Biodiversität und Naturausstattung im Himalaya. Erfurt: Verein der Freunde und Förderer des Naturkundsmuseums Erfurt. Vol.2. S.179-243.

Schmidt J. 2012. New Pterostichus species from the Eastern Himalaya, with a revision of the atrox group of the subgenus Pseudethira Sciaky, 1996 (Insecta: Coleoptera: Carabidae: Pterostichini) // Hartmann M., Weipert J. (eds.). Biodiversität und Naturausstattung im Himalaya. Erfurt: Verein der Freunde und Förderer des Naturkundsmuseums Erfurt. Vol.4. S.225-257.

Sciaky R. 1994a. Straneostichus gen.n., a new genus and four new species from China (Coleoptera: Carabidae: Pterostichinae) // Ann. Naturhist. Mus. Wien. Bd.96B. S.189-198.

Sciaky R. 1994b. Revision of Pterostichus subg. Morphohaptoderus Tschitscherine, 1898 with description of ten new species from China (Coleoptera: Carabidae) // Koleopt. Rundsch. Bd.64. S.1-19.

Sciaky R. 1994c. Sinosteropus new subgenus and three new species of Pterostichus from China (Coleoptera Carabidae) // Ann. Mus. Sci. Nat. Brescia. 1993. Vol.29. P.193-201.

Sciaky R. 1995. Pterostichus (Anomostichus) anomostriatus, new subgenus and new species from China (Coleoptera, Carabidae) // Entom. Basil. Bd.18. S.61-64.

Sciaky R. 1996a. Straneostichus farkaci sp.n. from China (Coleoptera: Carabidae: Pterostichinae) // Klappalekiana. Vol.32. P. $85-88$.
Sciaky R. 1996b. New taxa and new synonyms among Pterostichinae from Asia // Entomofauna. Bd.17. H.29. S.429-440.

Sciaky R. 1996c. Circinatus new subgenus and three new species of Pterostichus from China (Coleoptera Carabidae) // Ann. Mus. Sci. Nat. Brescia. 1994. Vol.30. P.217-231.

Sciaky R. 1997. New subgenera and new species of Pterostichini from China (Coleoptera, Carabidae) // Boll. Mus. Stor. Nat. Venezia. 1996. Vol.47. P.153-176.

Sciaky R., Allegro G. 2010. Two new subgenera and two new species of Pterostichus from China (Coleoptera, Carabidae) // Boll. Mus. Stor. Nat. Verona. Vol.37. Bot. \& Zool. P.113-122.

Sciaky R., Faccini S. 2003. A revision of Pterostichus subgenus Sinosteropus, with description of twenty-seven new taxa from China and India // Boll. Mus. Reg. Sci. Nat. Torino. Vol.20. No.2. P.401-438

Sciaky R., Wrase D.W. 1997. Twenty-nine new taxa of Pterostichinae from Shaanxi (Coleoptera, Carabidae) // Linzer Biol. Beitr. Bd.29. Hf.2. S.1087-1139.

Shi H., Sciaky R., Liang H., Zhou H. 2013. A new subgenus Wrasiellus of the genus Pterostichus Bonelli (Coleoptera, Carabidae, Pterostichini) and new species descriptions // Zootaxa. Vol.3664. No.2. P.101-135.

Shi H., Liang H. 2015. The genus Pterostichus in China II: the subgenus Circinatus Sciaky, a species revision and phylogeny (Carabidae, Pterostichini) and new species descriptions // Zookeys. Vol.536. P.1-92.

Straneo S.L. 1939. Nuovi Pterostichini (Coleoptera Carabidae). Nota II // Mem. Soc. Ent. Ital. Vol.18. F.1. P.117-123.

Straneo S.L. 1949. Nuovi Pterostichini (Coleoptera Carabidae) (V nota) // Bull. Inst. Sci. Nat. Belg. T.25. No.21. P.1-9.

Straneo S.L. 1979. Neue orientalische Arten der Gattungen Lesticus Dejean und Pterostichus Bonelli // Deutsch. Ent. Z. N.F. Bd.26. Hf. 1-3. S.43-46.

Straneo S.L. 1984. Two new species of Pterostichini (Coleoptera, Carabidae) in the collections of the Museum of Natural History of the Humboldt University of Berlin // Mitt. Zool. Mus. Berlin. Bd.60. S.263-265.

Wrase D.W., Smidt J. 2006. Description of a new subgenus and five new species of the genus Pterostichus Bonelli, 1810 (Coleoptera, Carabidae, Pterostichini) from northern Myanmar and Yunnan // Veröff. Naturkundmus. Erfurt. Bd.25. S.203-215. 